University of Louisville ThinkIR: The University of Louisville's Institutional Repository

Electronic Theses and Dissertations

$5-2016$

\title{
Modulation of cell death signaling and cell proliferation by the interaction of homoserine lactones and Paraoxonase 2.
}

Aaron Mackallan Neely

University of Louisville

Follow this and additional works at: https://ir.library.louisville.edu/etd

Part of the Bacteriology Commons, Biochemistry Commons, Cancer Biology Commons, Cell Biology Commons, Molecular Biology Commons, and the Other Biochemistry, Biophysics, and Structural Biology Commons

\section{Recommended Citation}

Neely, Aaron Mackallan, "Modulation of cell death signaling and cell proliferation by the interaction of homoserine lactones and Paraoxonase 2." (2016). Electronic Theses and Dissertations. Paper 2468.

https://doi.org/10.18297/etd/2468

This Master's Thesis is brought to you for free and open access by ThinkIR: The University of Louisville's Institutional Repository. It has been accepted for inclusion in Electronic Theses and Dissertations by an authorized administrator of ThinkIR: The University of Louisville's Institutional Repository. This title appears here courtesy of the author, who has retained all other copyrights. For more information, please contact thinkir@louisville.edu. 


\title{
MODULATION OF CELL DEATH SIGNALING AND CELL PROLIFERATION BY THE INTERACTION OF HOMOSERINE LACTONES AND PARAOXONASE 2
}

\author{
By
}

\author{
Aaron Mackallan Neely \\ B.S., Paul Quinn College, Dallas, TX, 2007 \\ M.S., University of North Texas, Denton, TX 2012
}

\section{A Thesis}

Submitted to the Graduate Faculty of the University of Louisville School of Medicine in Partial Fulfillment of the Requirements for the Degree of

Master of Science in Pharmacology and Toxicology

Department of Pharmacology and Toxicology

University of Louisville

Louisville, Kentucky

May, 2016 
Copyright 2016 by Aaron Mackallan Neely

All rights reserved 



\title{
MODULATION OF CELL DEATH SIGNALING AND CELL PROLIFERATION BY THE INTERACTION OF HOMOSERINE LACTONES AND PARAOXONASE 2
}

\author{
By
}

Aaron Mackallan Neely

B.S., Paul Quinn College, Dallas, TX, 2007

M.S., University of North Texas, Denton, TX 2012

A Thesis Approved on

March, $29^{\text {th }}, 2016$

Thesis Committee:

\section{Chi Li, Ph.D.}

\section{Leah Siskind, Ph.D.}

John W Eaton, Ph.D.

Brian Wattenberg, Ph.D.

Thomas Mitchell, Ph.D. 


\section{DEDICATION}

This Thesis is dedicated to my dear aunt, Sr. Jacinta Neely O.S.B and uncle Alpheus Neely Jr. for their unconditional love, support and encouragement. They taught me how to maximize limited resources to obtain a desired end goal. They encouraged me to transcend beyond socioeconomic limitation and exceed the expectations of others, whether negative or positive. Growing up, Uncle Junior instilled in me a sense of pride and self-worth. Aunt Jacinta showed me that I could be more than my environment allowed and imparted in me valuable lessons such as "Procrastination is the thief of time" and "Your writing is an accurate reflection of who you are". Aunt Jacinta has been a source of spiritual guidance and discipline and Uncle Junior was the only father figure I knew. Thank you both and may God bless guide and protect you. 


\section{ACKNOWLEDGEMENTS}

Foremost, I would like to thank our Almighty God for giving me this opportunity to further my education and for giving me guidance, favor and good health.

To my mentor Dr. Chi Li, I extend my deepest and sincerest gratitude for his acceptance, tutelage, and endless support. I am appreciative of his guidance, training and encouragement throughout my research. Without his incredible patience, this process would've been an overwhelming undertaking.

I'm indebted to Dr. Gavin Arteel for his advice, direction and timely wisdom, Dr. Leah Siskind for her support and endless encouragement and Dr. Christopher States for his stern support, for demanding and expecting my absolute best, and his unrelenting confidence in my abilities.

My thanks and appreciation is also extended to my research committee; Drs. Leah Siskind, John Eaton, Thomas Mitchell and Brian Wattenberg, for their enthusiasm, advice and constructive input during this process. Special thanks also go out to Cindy and Randy Albury, Richard Rankin, Shanice V Hudson, Amber Sweat and the Sweat family, Trevor Stephen, Lucia Kinteh, Nicole PhillipFelix and Denicia Briggs for their support, encouragement and well wishes. I would like to extend thanks to past and present members of Chi Li's Laboratory for their continued support and assistance.

Finally, I would like to thank my dear mother (Angela Neely), father (Nathaniel Knowles), step-mother (Winifred Knowles), aunt (Sr. Jacinta Neely O.S.B), uncle 
(Alpheus Neely Jr.), sister (Anastasia Carey and Amanda Johnson) and brother (Adam Johnson) for their unconditional love and support. I would not have been able to complete this thesis without their continued prayer, love and encouragement. 


\title{
ABSTRACT
}

\section{MODULATION OF CELL DEATH SIGNALING AND CELL PROLIFERATION BY THE INTERACTION OF HOMOSERINE LACTONES AND PARAOXONASE 2}

\author{
Aaron Mackallan Neely
}

March, 29th, 2016

Pseudomonas aeruginosa produces N-(3-oxododecanoyl)-homoserine lactone (C12) as a quorum-sensing molecule that functions to facilitate bacteria-bacteria communication. $\mathrm{C} 12$ has also been reported to affect many aspects of human host cell physiology, including evoking cell death in various types of cells. However, the signaling pathway(s) leading to C12-triggerred cell death remains unclear. To clarify cell death signaling induced by $\mathrm{C} 12$, we examined mouse embryonic fibroblasts (MEFs) deficient in one or more caspases. Our data indicate that, unlike most apoptotic inducers, C12 evokes a novel form of apoptosis in cells, probably through the direct induction of mitochondrial membrane permeabilization. Previous studies indicate that $\mathrm{C} 12$ requires the lactonase/arylesterase paraoxonase 2 (PON2) to exert its cytotoxicity on MEFs. PON2 is known to function as a lactonase to cleave C12. We found that PON2 was overexpressed in tissues from non-small cell lung carcinoma (NSCLC) patients and oncogenically transformed human bronchia/tracheal epithelial 
(NHBE) cells. Reducing PON2 expression in NSCLC cell lines as well as several non-transformed cell lines rendered them resistant to C12. However, PON2 expression is only important for the proliferation of NSCLC cell but not that of their untransformed counterparts, indicating that PON2 mediates apoptosis independently of its function to modulate cell proliferation. Overall, our results reveal a unique mitochondrial apoptotic signaling pathway triggered by C12/PON2 interaction and PON2 plays distinct roles in apoptosis signaling and cell proliferation. 


\section{TABLE OF CONTENTS}

PAGE

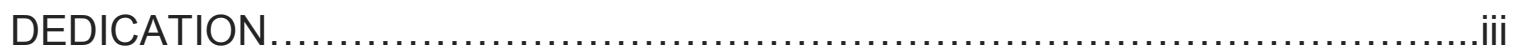

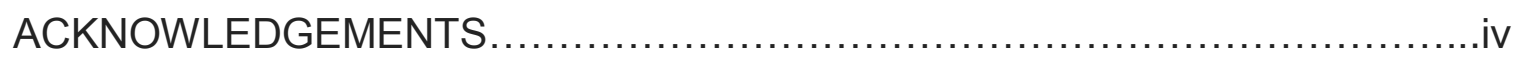

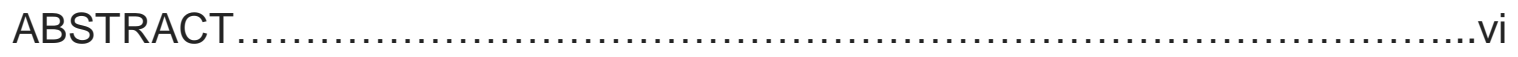

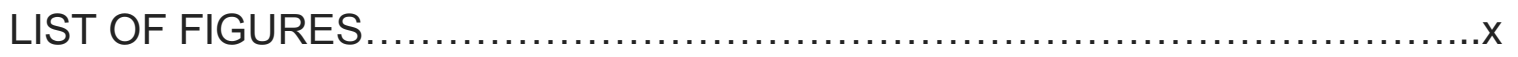

CHAPTER 1: INTRODUCTION ........................................

$1.1 \quad$ Programmed cell death Apoptosis............................

1.2 Regulation of Apoptosis....................................

1.3 Biological Importance of Apoptosis............................

1.4 The pathways of Apoptosis................................

1.4.1 The Intrinsic pathway of apoptosis....................5

1.4.2 The Extrinsic pathway of apoptosis..................

1.4.3 The Mixed pathway of apoptosis.....................

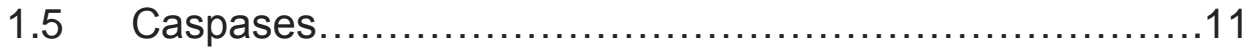

$1.6 \quad$ The Bcl-2 proteins........................................12

1.7 Other cell death modalities-Autophagy and Necrosis..........13

$1.8 \quad \mathrm{~N}$-(3-oxododecanoyl)-homoserine lactone (C12) ............14

1.9 Paraoxonase 2 (PON2) ....................................16

Chapter 2: MATERIALS AND METHODS ................................18 


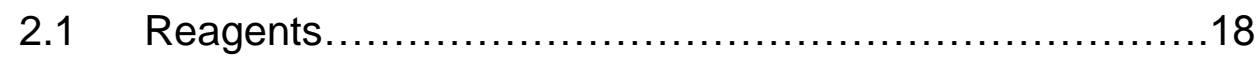

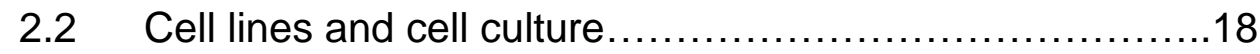

2.3 Cell viability/Death assays ...............................20

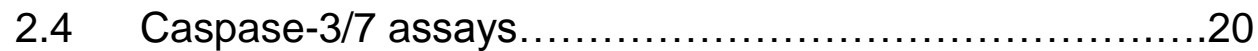

$2.5 \quad$ Western blot analysis.....................................21

2.6 Measuring $\Delta \psi_{\text {mito }}$ using imaging microscopy of $\mathrm{JC} 1 \ldots \ldots \ldots 21$

2.7 Detection of the release of cytochrome $\mathrm{c}$ from

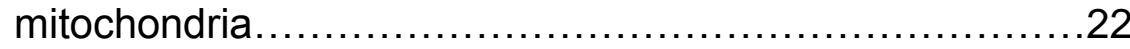

2.8 Electrophysiological experiments .........................22

2.9 Immunofluorescence microscopy $\ldots \ldots \ldots \ldots \ldots \ldots \ldots \ldots \ldots \ldots \ldots \ldots \ldots \ldots \ldots \ldots \ldots \ldots . . .23$

2.10 Cell cycle analysis and cell proliferation assay ................24

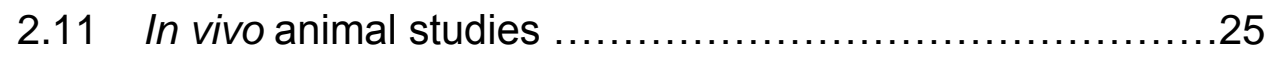

2.12 Statistical analysis.............................................

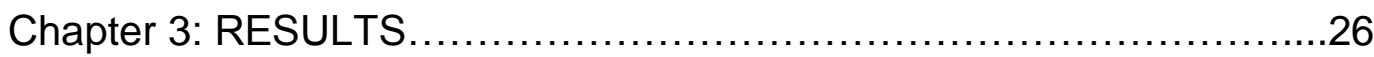

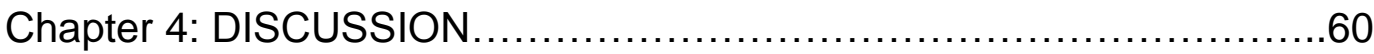

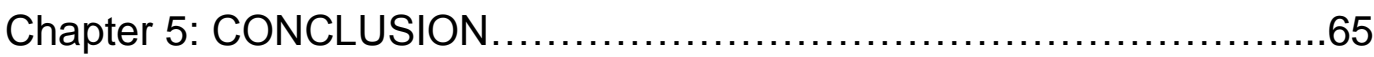

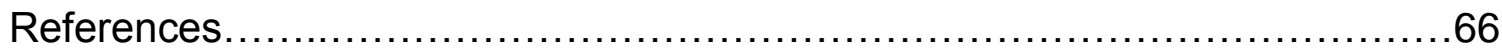

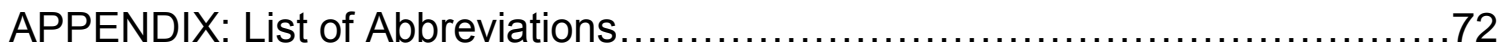

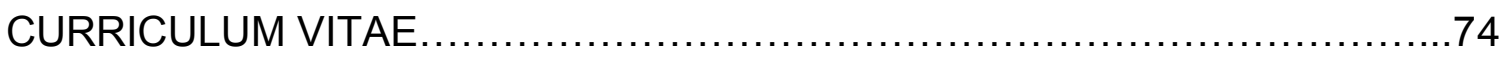




\section{LIST OF FIGURES}

PAGE

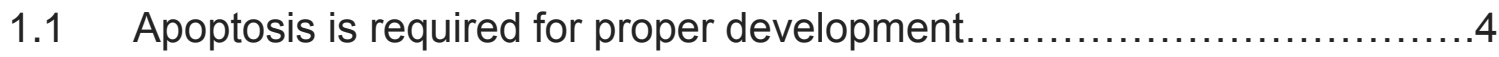

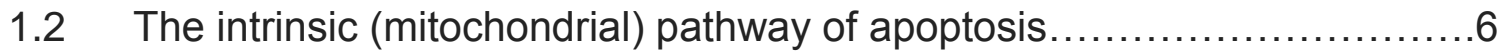

1.3 The extrinsic (death receptor) pathway of apoptosis $\ldots \ldots \ldots \ldots \ldots \ldots \ldots \ldots . . . . \ldots$

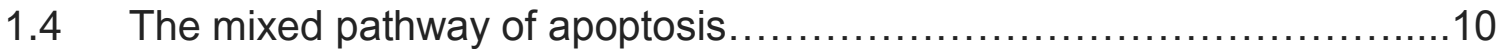

3.1 Caspase-3 and Caspase-7 were required for $\mathrm{C} 12$ induced cell death ....27

3.2 Caspase-3 and Caspase-7 were not required for mitochondrial

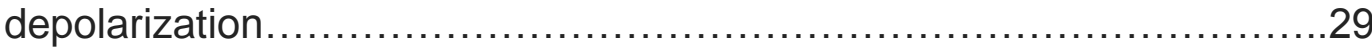

3. 3 C12-induced mitochondrial outer membrane permeabilization occurs upstream of caspase $3 / 7$ activation

3. 4 Caspase-8 and Caspase-9 plays distinct roles in C12 induced apoptosis

3. 5 C12 induced mitochondrial potential decrease is independent of caspase8 and caspase- 9

3. 6 C12 induced caspase-9 activation occurs downstream of mitochondrial membrane permeabilization

3. 7 C12 directly induces mitochondrial outer membrane permeabilization (MOMP) in vitro.

3. 8 C12 forms channels with large conductance in phospholipid membrane in vitro

3. 9 C12 inhibits LLC tumor growth and induces tumor cell apoptosis in vivo in a dose-dependent fashion. 
3.10 C12 induces tumor apoptosis cell death independent of anti-apoptotic Bcl-

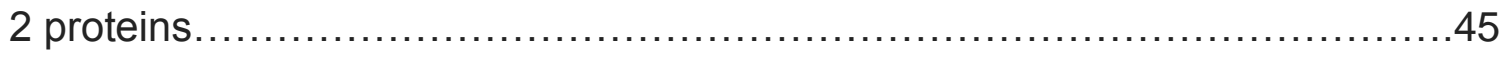

3.11 C12-induced tumor cell apoptosis is independent of Bak and Bax.......47

3.12 PON2 expression is enhanced in human lung tumor tissues and

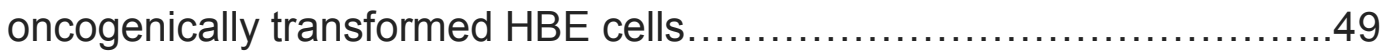

3.13 PON2 is required in $\mathrm{C} 12$ cytotoxicity in human lung tumor cells..........51

3.14 Murine PON2 sensitizes human tumor cells with reduced endogenous

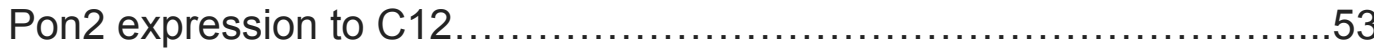

3.15 PON2 is essential for C12 triggered cell death in HEK-293T and HBE cells .55

3.16 PON2 is essential for human lung tumor cell proliferation but not non transformed cell proliferation

3.17 Deficiency in PON2 expression induces G1 cell cycle arrest of A549 cells .59 


\section{CHAPTER 1: INTRODUCTION}

Tissue differentiation and homeostasis are tightly regulated by the BcL-2 regulated cellular suicide program, apoptosis $(2,3)$. Many human tumor cells acquire resistance to conventional chemotherapeutic drugs that depend on BcL-2 proteins. These neoplastic cells have been found to have an increased ratio of anti-apoptotic to pro-apoptotic Bcl-2 proteins. Thus, the discovery of novel drugs that are capable of overcoming apparent tumor cell BcL-2 protein dependent resistance to cell death is a major challenge. A promising anti-tumor approach is the identification of small molecules (as well as their cellular targets) that preferentially trigger tumor cell apoptosis, independent of tumor cell $\mathrm{Bcl}-2$ protein profile $(4,5)$. While several candidate compounds have been identified, most if not all of these drugs could only induce apoptosis independent of either antiapoptotic or pro-apoptotic Bcl-2 proteins; but not both (5-7). Conversely, the quorum-sensing molecule N-(3-oxododecanoyl)-homoserine lactone (C12) preferentially induces transformed cell apoptosis in vitro and inhibits transplanted tumor growth in vivo independent of both anti- and pro-apoptotic $\mathrm{Bcl}-2$ proteins; thereby making it an ideal candidate drug. Our preliminary data indicates that C12 triggers Bcl-2 protein-independent apoptosis, likely mediated by Paraoxonase 2 (Pon2). PON2 is known to function as a lactonase to cleave $\mathrm{C} 12$. Previous studies indicate that $\mathrm{C} 12$ requires the lactonase / arylesterase PON2 to exert its cytotoxicity $(8,9)$. 


\subsection{Programmed cell death-Apoptosis}

The word Apoptosis derives from Greek origin meaning "dropping off or falling off," and initially referred to the process by which leaves fell from trees or petals from flowers. Apoptosis is a biological phenomenon that consists of a programmed sequence of biochemical events that culminate in the selective elimination of damaged, infected and potentially neoplastic cells from the bodies of multicellular organisms $(10,11)$. Apoptosis is one of the most ubiquitously employed mechanisms by which the body disposes of cell debris or damaged cells without eliciting localized inflammation; due to leakage of cellular contents(12). This mode of cell death is a vital component of normal tissue development, disease progression and maintenance of tissue homeostasis. Additionally, it serves as a means of defense against the development and advancement of cancer (13). The biochemical events that result in the occurrence of Apoptosis also elicit a large number of morphological changes in cells including cell shrinkage, blebbing of the membrane, condensation and fragmentation of nuclear material and the formation of apoptotic bodies.

\subsection{Regulation of apoptosis}

Apoptosis is under stringent genetic control and can be activated by stimuli from multiple sources. It is initiated in response to specific developmental signals or in the presence of various stimuli including the reduction of essential growth factors, the activation of Tumor Necrosis Factor receptors (TNFR), DNA damage, loss of 
cellular attachment, decreases in the local concentration of tissue morphogens and major alterations in homeostatic state of the cell $(14,15)$.

Excess or limited apoptosis can disrupt tissue homeostasis of multicellular organisms. When apoptosis occurs more frequently than cell proliferation does, neurodegenerative disorders are exacerbated. Further to this, the dysregulation of apoptosis has been implicated in the ontogeny and progression of many disease states including many cancers and neurodegenerative disorders such as Alzheimer's, Huntington's and Parkinson's diseases (16-18). Conversely, insufficient apoptosis can precipitate cancer development and progression $(19,20)$. Thus, tight regulation between apoptosis and cell proliferation is imperative for the viability of all multicellular organisms.

\subsection{Biological significance of apoptosis}

Apoptosis has long been recognized as a critical regulatory component of the development process. The role of apoptosis in development has been investigated and well established in three organisms: Nematodes (Caenorhabditis elegans), Fruit Flies (Drosophila melanogaster) and mouse (Mus musculus). Apoptosis has been found to drive hemaphroditic development during embryogenesis in C. elegans and promote the completion of development in $D$. melanogaster(21). Studies have indicated that the inhibition of apoptosis elicits developmental impediments, disorders and/or death $(13,22)$. 
In early mammalian development, apoptosis is instrumental in the formation of synapses between neurons in the brain and the spinal cord as it facilitates the removal of excess neurons cells(23). Additionally, Apoptosis assists in tissue remodeling, molding and shaping of the body and organs and the detailing/separation of extremities (fingers and toes) by the removal of excess tissues. Inhibition or insufficient apoptotic signaling elicits malformed limbs and digits joined by soft tissue (Figure 1.1) (1).

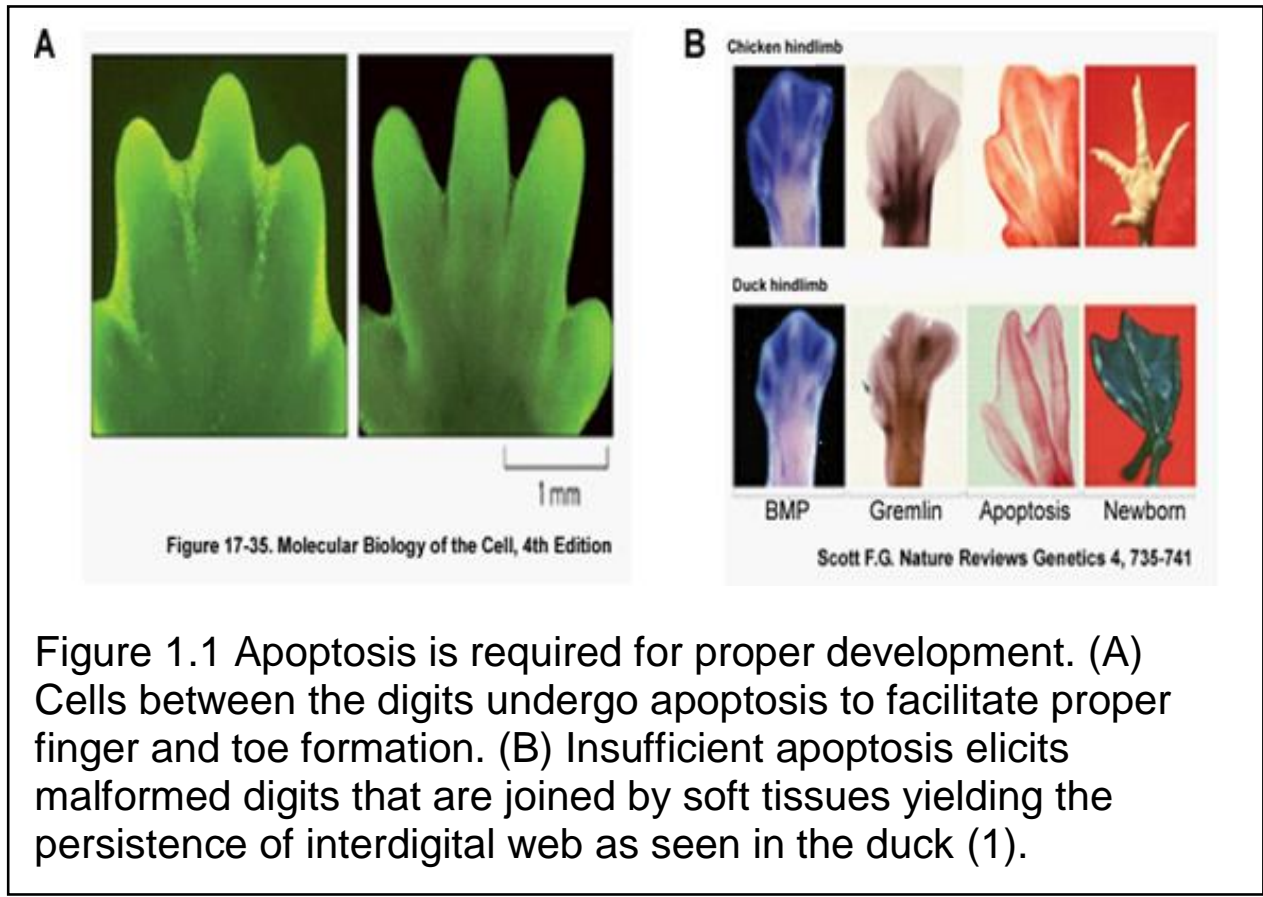

Apoptosis is also vital in the removal of those cells that may have deleterious effects on the organism. These include cells that are capable of participating in an autoimmune response as well as virally infected; and thus cytotoxic, T cells (24). Apoptosis facilitates the maintenance of tissue homeostasis. In the average adult, billions of cells die daily via apoptosis and are then replaced with new cells that originate from the body's stem cell populations (25). Apoptosis regulates the 
constant internal environment and normal tissue homeostasis. Under healthy and normal conditions, the rate of cell proliferation is approximately the same as the rate of apoptosis. This paradigm is essential for ensuring the viability of multicellular organisms. If this balance is disrupted, such that the occurrence of cell death is more frequent than that of cell replacement, the probability of the onset of neurodegenerative disorders is amplified. Moreover, inadequate apoptosis may elicit cancer development (26).

\subsection{The pathways of apoptosis}

Apoptosis typically occurs through one of three signaling pathways, namely the mitochondrial (intrinsic), the death receptor (extrinsic) and the mixed pathways.

\subsubsection{The intrinsic pathway of apoptosis}

Intracellular death signals are translocated to the mitochondria where they induce the mitochondria dependent intrinsic pathway of apoptosis. These signals activate the pro-apoptotic Bcl-2 proteins, which in turn lead to the formation of permeation channels on the outer mitochondrial membrane (OMM). These permeation channels facilitate the release of apoptogenic proteins (Diablo/Smac and cytochrome c) from the mitochondrial inter-membrane space (IMS) into the cytosol. Upon release into the cytosol, Diablo/Smac and cytochrome c induce a cascade of caspase reactions that culminate in the occurrence of apoptosis(27). Cytochrome c activates apoptotic protease factor 1 (apaf1), which promotes the transition of procaspases to their active caspase form. Diablo/Smac promotes 
apoptosis through direct interaction with inhibitors of apoptosis proteins (IAPs), thereby impeding their ability to inactivate caspases (Figure 1.2) $(28,29)$.

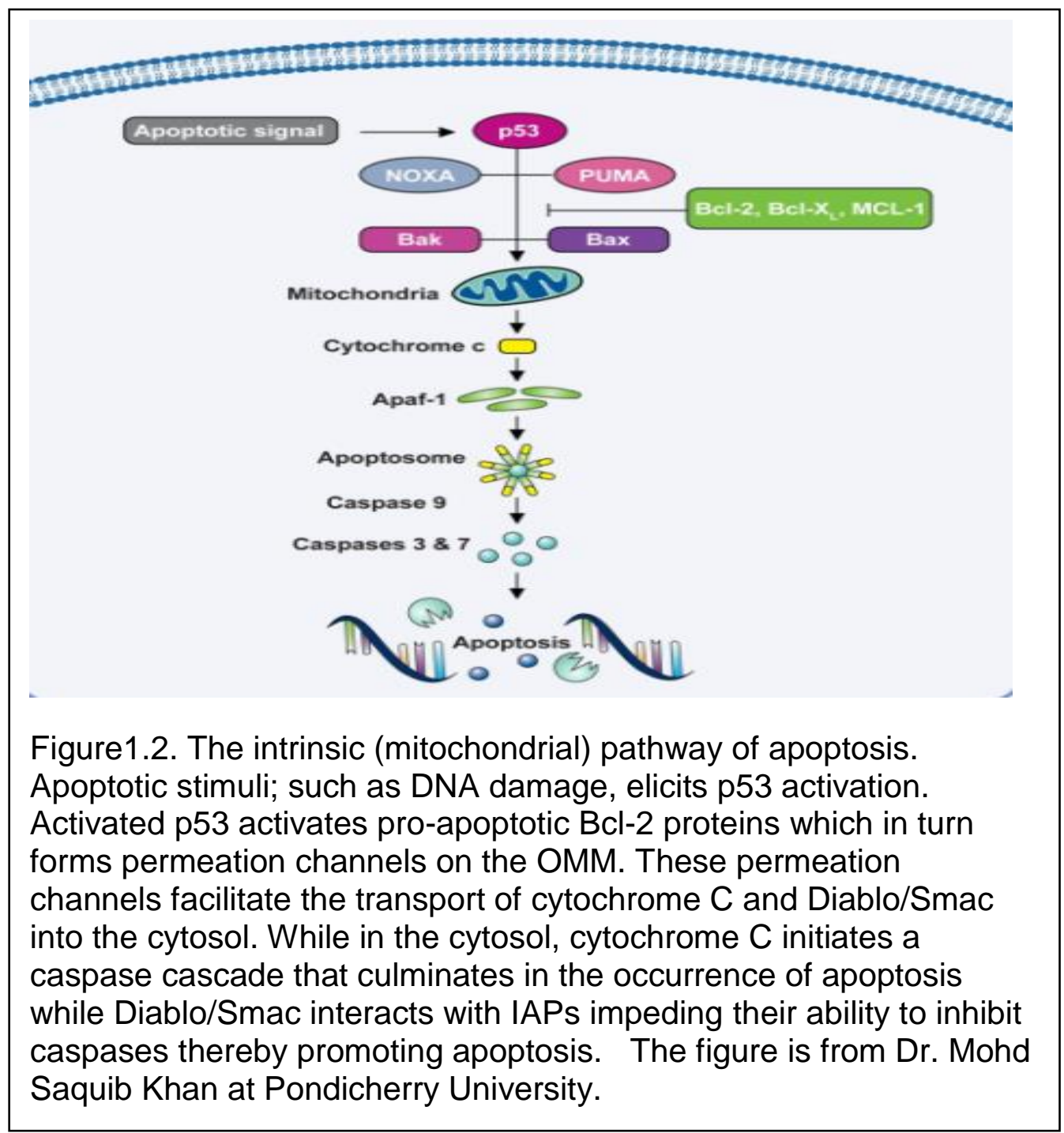




\subsubsection{The extrinsic pathway of apoptosis}

In contrast to the intrinsic apoptotic pathway, death signals for extrinsic apoptotic pathways are initiated from the outside of the cell. Induction of the extrinsic apoptotic pathways does not involve the mitochondria, involvement of the $\mathrm{Bcl}-2$ protein family or the release of cytochrome $\mathrm{c}$ forms the mitochondrial IMS to the cytosol. In this pathway, specific death ligands such as tumor necrosis factor (TNF), Fas Ligand (FasL) or TNF-related apoptosis-inducing ligand (TRAIL) binds to their respective specific transmembrane death receptors including FAS, tumor necrosis factor receptor 1 (TNFR1), p75, DR4(30).

The binding of death ligands to their respective specific death receptor promotes the collection and recruitment of the adaptor protein Fas-associated death domain (FADD) and the inactive forms of the initiator caspases 8 and 10 (procaspases 8 and 10), thus allowing for the formation of the death-inducing signaling complex (DISC). The DISC transports the procaspase molecules in close proximity, thereby ensuring access for their autocatalysis and eventual release into the cytosol (31-35). Caspase 8 or 10 will then activate the effector caspases $3 / 7$ in a cascade precipitated by caspase-mediated reactions that will culminate in the occurrence of apoptosis. 


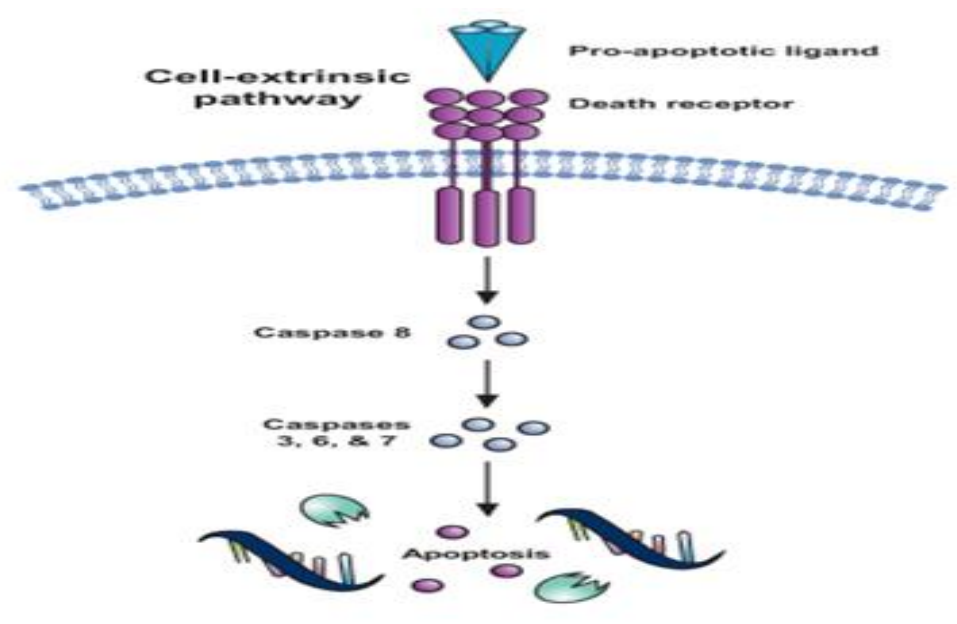

Figure 1.3. The extrinsic (death receptor) pathway of apoptosis. Extrinsic apoptotic signaling is generated extracellularly with the binding of death ligands to specific transmembrane death receptors. Activation of death receptors elicit clustering and recruitment of the adaptor molecule FADD, procaspase 8,10 resulting in the formation of the DISC. DISC formation activates caspase 8, 10. Caspase 8, 10 then activates caspase $3 / 6 / 7$ and leads to apoptosis. The figure is from Dr. Mohd Saquib Khan at Pondicherry University. 


\subsubsection{The mixed pathway of apoptosis}

There exist certain instances where the induction of apoptotic signaling cascades from external sources can also elicit the activation of both intrinsic and extrinsic apoptotic pathways. This phenomenon is known as the mixed apoptotic pathway and entails death stimuli that are generated extracellularly causing the activation of pro caspase 8 , pro caspase 10 , and formation of the DISC; in the same manner as observed in the extrinsic apoptotic pathway. The DISC formation will ultimately lead to autocatalysis and the eventual activation of caspase 8 and 10 (31-35). When caspase 8 is activated, it can enter one of two routes: (i) it can activate the effector caspases 3, 6 and 7, thereby eliciting apoptosis via the extrinsic pathway or (ii) it can enter the intrinsic apoptotic pathway via interaction with the Bcl-2 protein family. In this instance, caspase 8 will cleave the inactive pro-apoptotic BH3-only protein "Bid" into its truncated and active form tBid. The tBid then activates the Bcl-2 proteins Bax and Bak at the OMM. Bak and Bax then undergo conformational changes as well as oligomerization thereby yielding the formation of permeation pores on the OMM. Permeation pore formation elicits the release of cytochrome $\mathrm{c}$ and Diablo/Smac from the mitochondrial IMS into the cytosol. Once in the cytosol, cytochrome c and Diablo/Smac exert their proapoptotic effects in the same fashion as they do in the intrinsic apoptotic pathway $(27,36)$. 


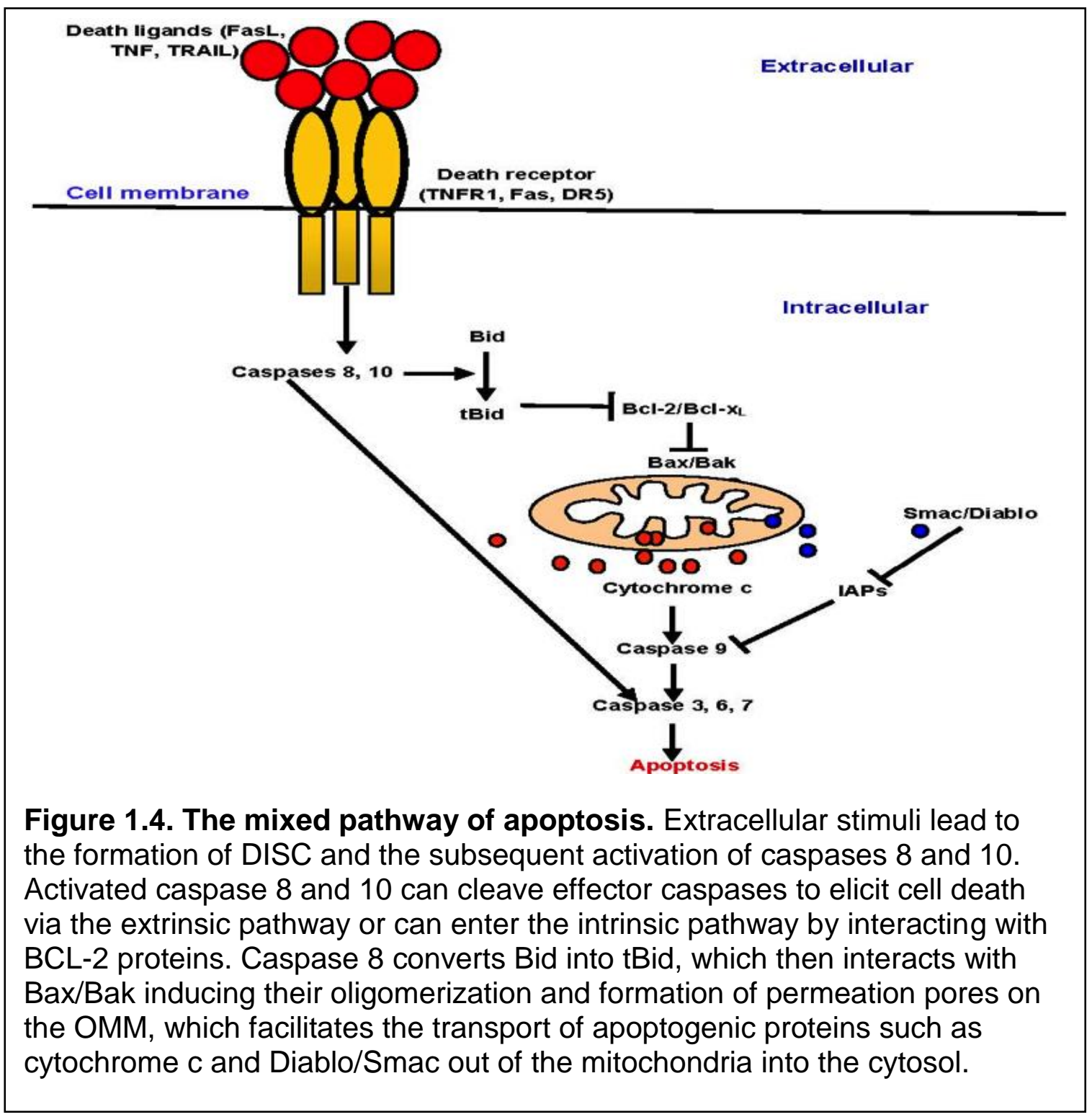




\subsection{Capases}

The caspases and the $\mathrm{Bcl}-2$ protein family are primary regulators of Apoptosis. The caspases are a group of cysteine proteases, which cleave proteins at sites that are proximal to aspartic acid residues(37). Caspase activation is typically considered the molecular hallmark of apoptosis(38). Caspases exist in their inactive forms (pro caspase), and become activated during apoptosis by proapoptotic proteins(39).

While 12 caspases have been identified to date, not all play a role in the regulation of apoptosis. For instance, caspase 1 is instrumental in the regulation of biological processes that are unrelated to cell death including red blood cell and skeletal muscle myoblast maturation. In contrast, caspase 14 is critical in skin cell development(40).

There are two classes of caspases involved in apoptosis namely the initiator (apical) and the effector (executioner) caspases. The initiator caspases include caspases 2, 8, 9 and 10 and are activated in response to upstream apoptotic stimuli. The initiator caspases cleave and process the effector caspases 3, 6 and 7. Upon activation, the effector caspases trigger cell death by degrading critical intracellular structural proteins. 


\subsection{The Bcl-2 proteins}

The Bcl-2 family of proteins is a major regulator of the intrinsic pathway of apoptosis. Their names derived from B-cell lymphoma/leukemia 2, and are the second member of a collection of proteins initially discovered during chromosomal translocations involving chromosomes 14 and 18 in human follicular lymphomas (41). There are approximately 20 different members of the $\mathrm{Bcl}-2$ protein family. Bcl-2 protein family members all share one to four homologous $\mathrm{Bcl}-2$ homology $(\mathrm{BH})$ domains that are important for homo and hetero-dimeric interactions among different family members. Bcl-2 proteins are either pro-apoptotic or anti-apoptotic $(2,3,14)$ depending on the amount of $\mathrm{BH}$ domains and their ability to regulate apoptosis(42).

Pro-apoptotic $\mathrm{Bcl}-2$ proteins are important for the initiation and stimulation of the intrinsic apoptotic pathway. These proteins are divided into two structurally and functionally distinct categories: multi-domain and $\mathrm{BH} 3-$ only $\mathrm{Bcl}-2$ proteins(43). Multi-domain pro-apoptotic Bcl-2 proteins Bak, Bax and Bok share three $\mathrm{BH}$ domains $(\mathrm{BH} 1-\mathrm{BH} 3)$. They are responsible for the formation of permeation channels on the OMM that disturbs mitochondrial membrane integrity during apoptosis. This facilitates the release of apoptogenic proteins from the mitochondria into the cytosol (44). Bak and Bax are ubiquitously expressed in all tissues while Bok is present only in reproductive cells (44). Bax and Bak are localized in different subcellular compartments of healthy cells. In the presence of death stimuli Bax undergoes conformational changes at both the amino- and 
carboxyl- termini eliciting its translocation from the cytosol to the $\mathrm{OMM}$ and the eventual formation of large oligomeric complexes. Bak is localized solely in the mitochondria and upon apoptotic stimuli, will undergo conformational changes elicit the formation of oligomeric complexes $(45,46)$. The oligomeric form of Bax and Bak form permeation pores on the OMM (47). These permeation channels mediate the release of pro-apoptotic proteins cytochrome $\mathrm{c}$ and Smac/Diablo from the IMS of the mitochondria to the cytosol where they exert their effects.

\subsection{Other cell death modalities - Autophagy and Necrosis}

Autophagy is a tightly regulated, ordered cell death process. It is self-degradative and essential for the maintenance of the balance of sources of energy at critical stages of development as well as in response to nutrient deprivation(48).

Autophagy is also responsible for the removal of damaged organelles, misfolded and aggregated proteins(49) and the elimination of intracellular pathogens(50).

The deregulation of autophagy has been implicated in non-apoptotic cell death. Autophagy can be selective or non-selective in the removal of specific organelles, ribosomes and protein aggregates(51). Furthermore, autophagy promotes cellular senescence and cell surface antigen presentation. It protects against genomic instability and is critical in the prevention of necrosis(50). Thus, autophagy has a key role in the prevention of diseases including cancer, neurodegeneration, liver diseases, autoimmune diseases, cardiomyopathy and infections. Increased endocytosis, vacuolation, membrane blebbing and nuclear condensation are all characteristic morphological hallmarks of autophagy. This 
type of cell death is categorized as a defensive reaction that can elicit cell death or cell survival(50).

Another modality of cell death is necrosis. Necrosis is the irreversible loss of plasma membrane integrity(52). It is a form of cell injury that results in the premature death of cells in living tissue by autolysis. This type of cell death lacks the features of apoptosis and autophagy, and typically is considered uncontrolled $(52,53)$. Necrosis is typically connected to immoderate cell loss in human pathologies and can lead to local inflammation (54-56), thought to occur through the liberation of factors from dead cells that alert the innate immune system $(53,54,57)$. Necrosis is signaled by irreversible cytoplasmic alterations (condensation, fragmentation and loss of structure) and nuclear changes (pyknosis, karyolysis and karyorhexis) $(52,53)$. Infection, toxins and trauma can result in the unregulated digestion of cell components leading to necrosis.

\section{$1.8 \mathrm{~N}$-(3-oxododecanoyl)-homoserine lactone (C12)}

The gram-negative opportunistic bacterium Pseudomonas aeruginosa produces $\mathrm{N}$-(3-oxododecanoyl)-homoserine lactone (C12) as a quorum-sensing molecule used to facilitate bacteria-bacteria communication (7). Quorum sensing is a bacterial communication system that releases and detects small diffusible autoinducers $(8,58)$. This system is responsible for the regulation of bacterial gene expression in response to changes in cell population density(58). Gram positive and gram-negative bacteria employ quorum-sensing communication to 
regulate variety of physiological functions including: symbiosis, antibiotic production, conjugation, motility and biofilm formation(58). Mounting data has shown that $\mathrm{C} 12$ is involved in the regulation of bacterial virulence genes and also interacts with eukaryotic cells $(59,60)$. As a small, lipid-soluble and diffusible molecule, $\mathrm{C} 12$ readily enters cells of multiple tissues in the lungs of cystic fibrosis patients including fibroblasts, epithelial cells, leukocytes, and endothelial cells (9). Additionally C12 alters many aspects of eukaryotic cell physiology including the inhibition of the secretion of proinflammatory cytokines (61-64), activation of p53, and inhibition of events commonly associated with cell death (65-68). C12 has been shown to induce apoptosis in multiple types of cancer cells $(66,69-71)$. C12 induces apoptosis by inhibiting phosphatidylinositide3-kinases, arresting Akt/PKB pathway and attenuating STAT3 activity in breast carcinoma cells $(8,66)$. In pancreatic carcinoma cells, C12 induces apoptotic signaling and inhibits cell migration $(8,70)$. In colorectal cancer cells, $\mathrm{C} 12$ reduces the expression of thymidylate synthase while enhancing the activity of otherwise conventional chemotherapeutic agents including 5-fluorouracil (5-FU) (69). Comparative SAR analysis has indicated that long acyl side chains with a 3-oxo substitution are essential for C12's anti-cancer effect (69). However, the exact signaling pathway(s) leading to C12-triggered cell death remains unclear. Our preliminary studies indicate that C12-triggered tumor cell apoptosis occurs by selectively activating the mitochondria-specific intrinsic pathway through a novel mechanism that is independent of activities of both anti- and pro-apoptotic Bcl-2 proteins in human tumor cells. We also find that $\mathrm{C} 12$ induces apoptosis 
preferentially in oncogenically transformed but not in non-transformed human bronchial epithelial cells. Importantly, we discovered that C12 cytotoxicity is mediated through the lactonase activity of paraoxonase 2 (PON2).

\subsection{Paraoxonase 2 (PON2)}

PON2 is a ubiquitously expressed mammalian protein with anti-oxidant properties and lactonase/arylesterase activities $(72,73)$, and it rapidly hydrolyzes C12 to C12-acid, which becomes trapped and accumulates within human bronchial epithelial cells, particularly in mitochondria (74-77). PON2 is upregulated in many types of cancer, including lung cancer, enabling cancer cells to resist conventional therapeutic drugs $(78,79)$. PON2 expression also prevents oxidation and inflammation, but the detailed mechanisms remain unclear. This membrane-bound protein's expression is markedly elevated in several human non-small cell lung carcinoma (NSCLC) cell lines. Mutations in the Pon2 gene may be associated with vascular disease and a number of phenotypes related to diabetes.

An important anti-tumor approach is the identification of small molecules that preferentially trigger tumor cell apoptosis regardless of the Bcl-2 protein profile in tumor $(4,5)$. The quorum-sensing molecule $\mathrm{C} 12$ preferentially induces transformed cell apoptosis in vitro and inhibits transplanted tumor growth in vivo independent of both anti- and pro-apoptotic Bcl-2 proteins. The apoptosis cascade induced by $\mathrm{C} 12$ in tumor cells is unique, evident by its rapid pro- 
apoptotic effects, such as depolarization of mitochondrial membrane potential within minutes, release of cytochrome $c$ into the cytosol within one hour and detection of maximal activation of caspases within four hours. This distinctive pro-apoptotic feature of $\mathrm{C} 12$ has not been observed in any other apoptosis paradigms, which might be attributed to the ability of $\mathrm{C} 12$ or its metabolite(s) to directly permeabilize mitochondria (within minutes) without involving Bcl-2 proteins. Furthermore, lung tumor cells are resistant to conventional therapeutic drugs partially due to overexpression of paraoxonase 2 (PON2), a protein with anti-oxidant properties and lactonase/ arylesterase activities $(80,81)$. 


\section{CHAPTER 2: MATERIALS AND METHODS}

\subsection{Reagents}

$\mathrm{N}$-(3-oxododecanoyl)-homoserine lactone (C12) was purchased from Sigma (St. Louis, MO). Propidium iodide (PI) was obtained from Invitrogen (Carlsbad, CA). Unless otherwise stated, all reagents were dissolved in dimethyl sulfoxide (DMSO). Dulbecco's Modified Eagle's Medium (DMEM), penicillin/streptomycin, trypsin, and L-glutamine were obtained from Mediatech (Manassas, VA), and fetal bovine serum (FBS) was purchased from Gemini (Broderick, CA). CaspaseGlo assay 3/7 kit was purchased from Promega (Madison, WI). Antibodies (Abs) used for western blot analysis were anti- $\beta$-actin mAb (Sigma), anti-caspase-3 pAb (Cell signaling; Danvers, MA), anti-caspase-7 pAb (Cell signaling), anticaspase-8 pAb (Cell signaling), anti-caspase-9 pAb (Cell signaling), anti-Bax pAb (Santa Cruz; Dallas, TX), anti-Bak pAb (Millipore; Billerica, MA), anti-Bcl-2 mAb (Santa Cruz), anti-human PON2 (Abcam; Cambridge, MA), anti-murinePON2 (Antibodies-on-line; Atlanta, GA), peroxidase-conjugated goat anti-rabbit IgG (Thermo; Waltham, MA) and peroxidase-conjugated goat anti-mouse IgG (Thermo).

\subsection{Cell lines and cell culture} Immortalized mouse embryonic fibroblasts (MEFs) deficient in the expression of caspase-8 and their wild-type counterparts were provided by Professor David 
Vaux (Walter and Eliza Hall Institute of Medical Research, Parkville, VIC Australia). MEFs lacking caspase-9 and their wild-type counterparts were obtained from Professor Jerry Adams (Walter and Eliza Hall Institute of Medical Research). MEFs lacking caspase-3, caspase-7, caspase-3 and caspase-7, or their wild-type counterparts were obtained from Professor Richard Flavell (Yale University). HCT116 cells expressing different levels of Bak and Bax were obtained from Dr. Richard Youle (National Institutes of Health). NSCLC cell line A549 and NCI-H1299 cells were obtained from ATCC. A549 cells overexpressing $\mathrm{Bcl}-2$ were produced by retroviral infection as described previously (8). To generate $\mathrm{NCl}-\mathrm{H} 1299$ or A549 cells with reduced PON2 expression or vector control, we infected cells using respective lentiviral supernatants with $10 \mu \mathrm{g} / \mathrm{ml}$ polybrene. Stable cell lines were obtained by culturing cells in the medium containing $1.5 \mu \mathrm{g} / \mathrm{ml}$ puromycin. NHBE cells were purchased from Lonza (Walkersville, MD). hT/LT/Ras HBE cells were obtained from Professor Barrett Rollins (Harvard Medical School). Lewis Lung Carcinoma cells, $\mathrm{NCl}-\mathrm{H} 1299$ and A549 cells were cultured as described previously (8). NHBE and hT/LT/Ras cells were grown in BEGM supplemented with SingleQuots (LONZA). HCT116 cells were grown as described previously (8). Cells were all cultured in a $5 \% \mathrm{CO} 2$ humidified incubator at $37^{\circ} \mathrm{C}$. 


\subsection{Cell viability/Death assays}

The indicated MEF cell lines were plated in a 48-well tissue culture plate with 20,000 cells in each well and cultured for 24 hours. Following the treatment with different concentrations of $\mathrm{C} 12$, cells were harvested in the presence of $1.0 \mu \mathrm{g} / \mathrm{ml}$ propidium iodide $(\mathrm{PI})$. Cell viability was measured by $\mathrm{PI}$ exclusion using flow cytometry (FACSCalibur, Becton Dickinson) (FACScalibur, Beckon Dickinson; San Jose, CA). The percentage of cell death is determined as 100 minus the cell viability measurement.

\subsection{Caspase-3/7 activity}

Caspase-3/7 activities were measured using a Caspase-Glo assay kit (Promega, Madison, WI, USA) (82). In this assay, the proluminescent substrate containing the amino acid sequence Asp-Glu-Val-Asp (DEVD) is cleaved by activated caspase-3/7, resulting in the release of a luciferase substrate (aminoluciferin) and the production of luminescent signal. Briefly, 24 hours before the treatment, cells were plated in white-walled 96-well plates. At the indicated time points following treatment with various molecules, cells were mixed with CellTiter-Glo reagent and the luminescence was quantified by a Gemini EM microplate spectrofluorometer (Molecular Devices; Sunnyvale, CA) according to the manufacturer's protocols. Data were presented as relative fluorescence units (RFUs). 


\subsection{Western blot analysis}

Equal amounts of proteins $(30 \mu \mathrm{g})$ were separated on a $4-12 \%$ Bis-Tris gel (BioRad; Hercules, CA) and transferred onto PVDF membrane (Millipore; Billerica, MA). The membrane was incubated with appropriate primary or secondary antibodies either overnight at $4^{\circ} \mathrm{C}$ or at room temperature for 3 hours in $1 \mathrm{X}$ phosphate-buffered saline (PBS) containing 5\% (w/v) nonfat dry milk (Bio-Rad) and $0.2 \%(\mathrm{v} / \mathrm{v})$ Tween 20 . Protein levels were detected using the enhanced chemiluminescent detection system (Pierce; Rockford, IL) as described previously(83).

2.6. Measuring $\Delta \psi_{\text {mito }}$ using imaging microscopy of JC1

For imaging experiments to measure mitochondrial membrane potential $\left(\Delta \psi_{\text {mito }}\right)$, cells were incubated with growth media containing the $\Delta \psi_{\text {mito }}$ probe $\mathrm{JC} 1(10 \mu \mathrm{M})$ for 10 minutes at room temperature, and then washed three times with Ringer's solution to remove the extra dye. JC1-loaded cells were placed onto a chamber on the stage of a Nikon Diaphot inverted microscope. Cells were maintained at room temperature during the experiment. Treatments were made by diluting stock solutions into Ringer's solution at the concentrations stated in the text. Fluorescence imaging measurements of $\Delta \psi_{\text {mito }}$ were performed using equipment and methods that have been reported previously $(7,14)$. Briefly, a Nikon Diaphot inverted microscope with a Fluor $20 \mathrm{X}$ objective ( 0.75 numerical apertures) was used. A charge coupled device camera collected JC-1 emission images (green: 510-540 nm; red: 580-620 nm) during excitation at $490+/-5 \mathrm{~nm}$ using filter 
wheels (Lambda-10, Sutter Instruments, Novato, CA). Axon Imaging Workbench 5.1 (Axon Instruments, Foster City, CA) controlled filters and collection of data. Images were corrected for background (region without cells). Quantitative data are reported as $\mathrm{JC} 1$ fluorescence ratios normalized to minimal $\mathrm{JC} 1$ ratios obtained at the start of the experiment and maximal JC1 ratios obtained after treatment with $5 \mu \mathrm{M}$ FCCP.

\subsection{Detection of the release of cytochrome $\mathrm{c}$ from mitochondria} Mitochondria were purified from MEF cells as described previously (84). Isolated mitochondria were resuspended in buffer containing 12 mM HEPES ( $\mathrm{pH}$ 7.5), 1.7 mM Tris- $\mathrm{HCl}(\mathrm{pH}$ 7.5), $100 \mathrm{mM} \mathrm{KCl,} 140 \mathrm{mM}$ mannitol, $23 \mathrm{mM}$ sucrose, $2 \mathrm{mM}$ $\mathrm{KH} 2 \mathrm{PO} 4,1 \mathrm{mM} \mathrm{MgCl}$, $0.67 \mathrm{mM}$ EGTA, and 0.6 mM EDTA supplemented with protease inhibitors (Complete; Roche Diagnostics, Indianapolis, IN). After one hour incubation with $\mathrm{C} 12$ at $30^{\circ} \mathrm{C}$, mitochondrial vesicles were centrifuged at $10,000 \times \mathrm{g}$ for $10 \mathrm{~min}$, and vesicles were dissolved in 1×SDS-PAGE loading buffer. Proteins in the vesicle fractions were detected by Western blotting.

\subsection{Electrophysiological experiments}

Solvent free planar phospholipid membranes were formed across a $0.1 \mathrm{~mm}$ hole in a Saran partition by the monolayer method $(60,61)$. The monolayers were formed by layering the lipid solution $(0.5 \%(\mathrm{w} / \mathrm{v})$ diphytanoylphosphatidylcholine, $0.5 \%(\mathrm{w} / \mathrm{v})$ asolectin (polar extract of soybean phospholipids), and $0.05 \%(\mathrm{w} / \mathrm{v})$ cholesterol in hexane) on the surface of the aqueous solutions $(1.0 \mathrm{M} \mathrm{KCl}, 1 \mathrm{mM}$ 
$\mathrm{MgCl} 2$, and $5 \mathrm{mM}$ PIPES, $\mathrm{pH} 6.9$ ) on either side of the partition. The phospholipids were purchased from Avanti Polar Lipids. Calomel electrodes were used to interface with the aqueous phase. The membrane voltage was clamped using a high-quality operational amplifier in the inverted mode and the current recorded using Clampex 10.3 software. Data was low-pass filtered at $500 \mathrm{~Hz}$ when recorded. Typically $20-50 \mu \mathrm{L}$ of $0.7 \mathrm{mg} / \mathrm{ml} \mathrm{C12}$ (dissolved in $95 \%$ isopropanol, $5 \%$ DMSO) was dispersed with rapid stirring into a $5 \mathrm{~mL}$ aqueous solution on one side of the membrane, labeled "cis" side. All voltages referred to the cis side, the trans being held at virtual ground by the amplifier. Vehicle controls produced no conductance.

\subsection{Immunofluorescence microscopy}

MEF cells plated onto cover glasses 24 hours earlier were rinsed with Ringer's solution and incubated for 4 hours with either vehicle (DMSO) or $50 \mu \mathrm{M} \mathrm{C12} \mathrm{in}$ Ringer's solution. The immunofluorescence staining of cytochrome $\mathrm{c}$ and tom20 were carried out as described previously (Zhao et al., JBC, 2015). Images were captured using a Nikon Eclipse Ti confocal microscope (Nikon; Melville, NY) equipped with a PlanApo 60x, 1.42 NA oil immersion objective. To minimize variability for quantitative assessment, the same microscope settings were used across vehicle control and C12-treated samples for three individual experiments. Four to nine fields of view were captured to acquire a sample size of at least 100 cells for each individual experiment. Quantification of cytochrome c and tom20 percentage of overlap was performed using ImageJ $(\mathrm{NIH})$. For each image, 
Maximum Intensity Projections (MIPs) were first created for both the cytochrome c and tom20 channels. Using tom20 as a guide, regions of interest (ROIs) were drawn around the cytoplasm of the cells, and these ROls were copied onto the cytochrome $\mathrm{c}$ and tom20 MIPs. The percent area of pixels above a set threshold was calculated for every ROI (cell) for both cytochrome $\mathrm{c}$ and tom20. The thresholds, although set differently for cytochrome c and tom20, were kept the same for every image across control and C12-treated samples to reduce bias. Percent overlap between cytochrome $\mathrm{c}$ and tom20 was calculated as (percent area cytochrome c/percent area tom20) ${ }^{\star} 100$.

For immunofluorescence staining of tumor sections, tumor sections $(5 \mu \mathrm{m})$ were treated with antigen retrieval procedure by boiling in $10 \%$ Triton $x-100$, then slowly cooled down at room temperature. After incubating with the blocking buffer ( $1 \times$ PBS, $0.2 \%$ Triton $X-100,5 \%$ goat serum), the slides were incubated with antibodies against activated caspase-3 (Cell signaling) overnight at $4^{\circ} \mathrm{C}$. Following three 10-minute washes, slides were incubated with goat anti-rabbit IgG (Alexafluor-568, Invitrogen) for 1 hour. The fluorescence was visualized by confocal microscopy using a 40x CFI Plan Fluor objective (NA 0.6)

2.10. Cell cycle analysis and cell proliferation assay For cell cycle analysis, $5 \times 10^{5}$ cells were sedimented ( $300 \times \mathrm{g}$ for 5 minutes) and washed twice with $500 \mu \mathrm{l} 1 \times$ PBS. Cells were then fixed with $1 \mathrm{ml} 70 \%$ ethanol in $1 \times \mathrm{PBS}$ at $4^{\circ} \mathrm{C}$ overnight. After centrifugation, cells were washed twice with 1 
x PBS and resuspended in $500 \mu \mathrm{l} 1$ x PBS. $50 \mathrm{U}$ RNase A (Qiagen, Valencia, CA) were added to samples and incubated at $37^{\circ} \mathrm{C}$ for 1 hour. Five $\mu g$ propidium iodide was added to samples which were incubated for 30 minutes at $37^{\circ} \mathrm{C}$ before flow cytometric analysis. To evaluate cell proliferation, $1.5 \times 10^{4}$ cells were plated in wells of a 12-well plate and the total cell number was determined by using a hemocytometer.

\subsection{In vivo animal studies}

For transplanted tumors in C57BL/6 mice, eight-week old C57BL/6 female mice (Jackson Laboratories; Bar Harbor, ME) were inoculated subcutaneously (s.c.) with $1 \times 10^{6}$ Lewis Lung Carcinoma cells on the right flank. Tumors were measured daily with dull edged Vernier calipers $\left(V=L \times W^{2} / 2\right)$. After tumor size reached around $100 \mathrm{~mm}^{3}$, animals with size-matched tumors were divided into control group and $\mathrm{C} 12$ group. DMSO or $\mathrm{C} 12$ was administered intraperitoneally each day. At the end of the experiments, tumors were excised for apoptosis evaluation. TUNEL labeling was carried out by the Pathology Research Services Laboratory at University of Washington. The slides were scanned by a ScanScope CS digital slide scanner (Aperio; Vista, CA).

\subsection{Statistical analysis}

All experiments were performed in triplicate at least three times. Results are presented as mean \pm standard deviation. Statistical analysis was performed using Student's two tail t-test. A p value $<0.05$ was considered significant. 


\section{CHAPTER 3: RESULTS}

3.1 Caspase-3 and caspase-7 were required for C12-induced cell death. In multicellular organisms, cell death is a highly heterogeneous process in which several distinct, in some cases partially overlapping, cell signaling cascades can be activated (1). Although C12's ability to trigger the events commonly linked to apoptosis has been reported (References $56,60,63,65,66$ ), it is unclear whether other cell death signaling is involved. To thoroughly explore C12induced cell death signaling, we first investigate whether caspase-3 and caspase- 7 are essential to mediate cytotoxic effects of $\mathrm{C} 12$ Cytotoxicity of $\mathrm{C} 12$ was examined in MEF cells lacking only caspase-3 (caspase-3-KO), only caspase-7 (caspase-7-KO), or both of them as well as their wild-type (WT) counterparts (Figure 3.1A). C12 induced significant cell death in WT, caspase-3$\mathrm{KO}$ and caspase-7-KO MEF cells, whereas caspase-3/7-DKO MEF cells were completely resistant to $\mathrm{C} 12$ exposure (Figure 3.1B). Moreover, less cell death was observed in caspase-3-KO or caspase-7-KO MEFs than their wild-type counterparts, indicating that both caspase- 3 and caspase- 7 are involved in apoptosis signaling initiated by $\mathrm{C} 12$, although caspase- 3 appears to play a more prominent role. The essential role of caspase- 3 and caspase- 7 indicates that cell death induced by $\mathrm{C} 12$ is largely attributed to apoptosis. 
A

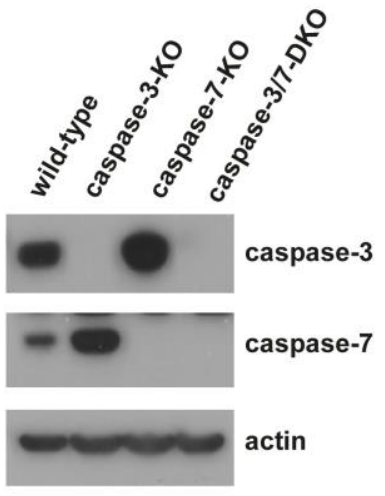

B

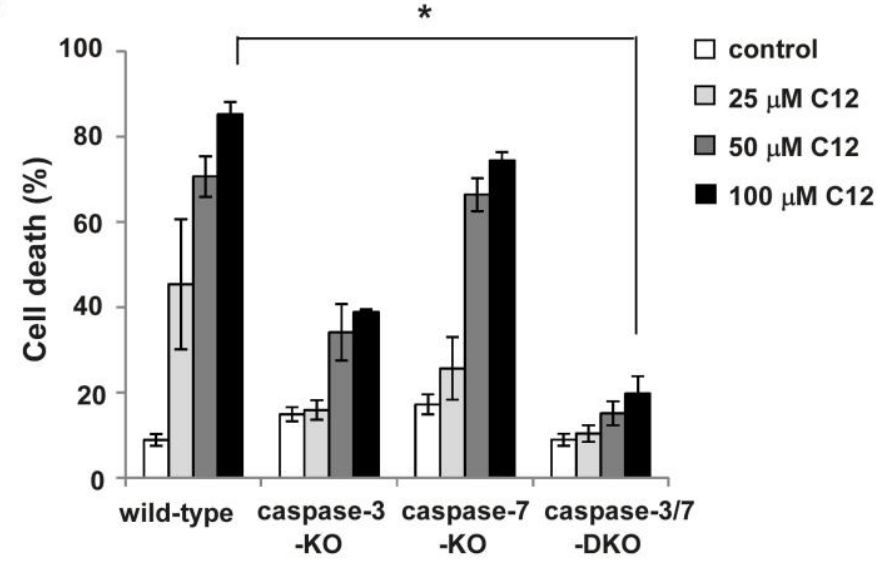

Figure 3.1. Caspase-3 and caspase- 7 were required for $\mathrm{C} 12$-induced cell death (A) Caspase-3 and caspase-7 expression in MEF cells was examined via western blot analysis. (B) The indicated MEFs were treated with various concentrations of $\mathrm{C} 12$ for 48 hours and cell viability was measured by propidium iodide exclusion using flow cytometry. Cell death data are shown as mean \pm standard deviations of 3 independent experiments. Asterisks indicate $\mathrm{P}<0.05\left(^{*}\right)$; Student's unpaired t test. 
3.2. Caspase-3 and caspase-7 were not required for mitochondrial depolarization.

Mitochondrial outer membrane permeabilization (MOMP) has been recognized to be a "no-return" step in both intrinsic and extrinsic apoptotic pathways (1). To further explore $\mathrm{C} 12$-initiated apoptotic signaling, we first studied the involvement of caspase-3 and caspase-7 in the key event of MOMP: depolarization of mitochondrial membrane potential $\left(\Delta \psi_{\text {mito }}\right)$. Depolarization of $\Delta \psi_{\text {mito }}$ was evaluated by determining the changes in fluorescence with the voltagedependent dye $\mathrm{JC} 1$ being released from mitochondria into the cytosol and nucleus. Within minutes of $\mathrm{C} 12$ exposure, mitochondria in MEFs were largely depolarized to a degree close to the complete depolarization of $\Delta \psi$ mito induced by the ionophore FCCP (Figure 3.2A). Importantly, depolarization of $\Delta \psi_{\text {mito }}$ occurred at similar levels in WT and caspase-3/7-DKO MEF cells upon C12 exposure, indicating that MOMP induced by $\mathrm{C} 12$ occurs upstream of "effector" caspase activation (Figure 3.2B). 


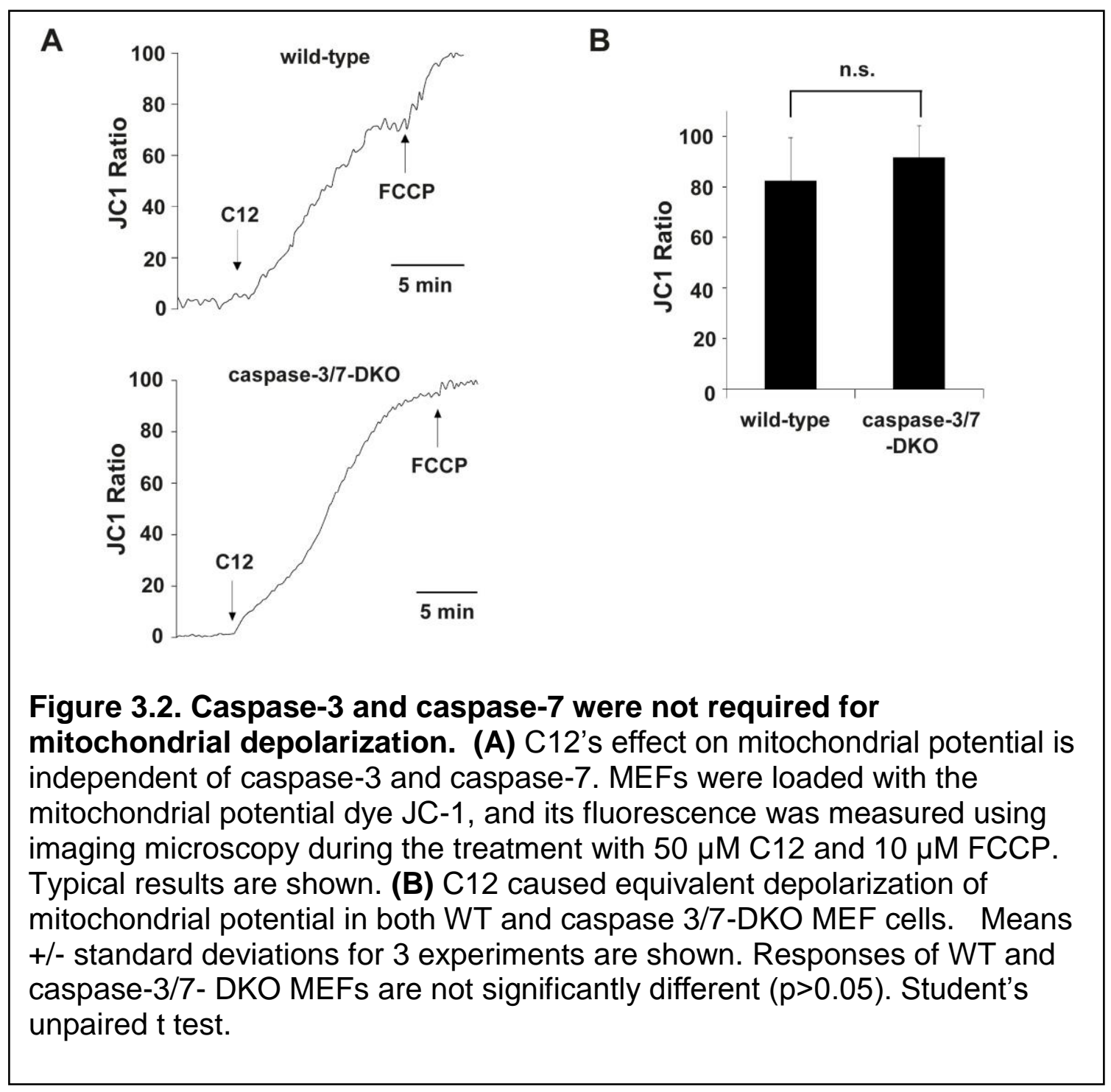


3.3. C12-induced mitochondrial outer membrane permeabilization occurs upstream of caspase-3/7 activation.

To validate these observations, we studied the involvement of caspase- 3 and caspase-7 in another key event of MOMP, cytochrome c release from mitochondria into the cytosol. We performed immunofluorescent studies to evaluate C12-evoked redistribution of cytochrome $\mathrm{c}$ to the cytosol/nuclei. Upon C12 treatment, intracellular distribution of cytochrome c was diffuse in the cytosol and nuclei in both WT and caspase-3/7-DKO MEFs, whereas Tom20 maintained its characteristic mitochondrial distribution, demonstrating that mitochondria in WT and caspase-3/7-DKO MEFs were permeabilized with cytochrome c released into the cytosol and diffused into the nuclei (Figure 3.3A). The redistribution of cytochrome $\mathrm{c}$ was evaluated by calculating the percentage of overlapping between cytochrome $\mathrm{c}$ and Tom20, and the results indicate that $\mathrm{C} 12$ caused equivalent cytochrome c release in WT and caspase-3/7-DKO MEFs (Figure 3.3B). Overall, our results provide more evidence that $\mathrm{C} 12$ triggers MOMP independent of caspase-3 and caspase-7 activation. 


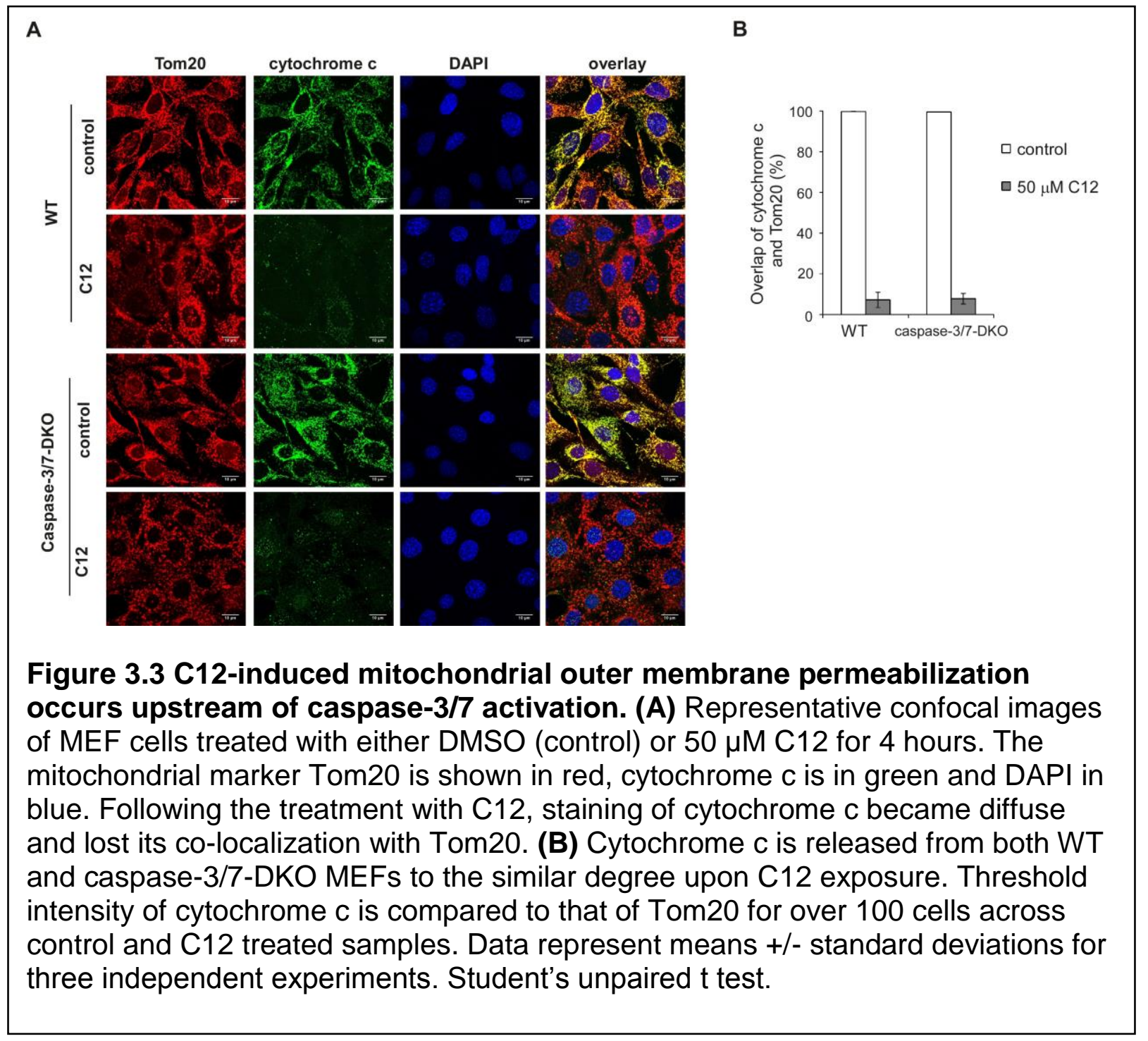


3.4. Caspase-8 and caspase-9 plays distinct roles in C12-induced apoptosis. While it has been shown that $\mathrm{C} 12$ induces an apoptotic modality of cell death, the exact signaling pathway remains unclear. It is well accepted that caspase-8 activity is characteristic of the extrinsic apoptotic pathway while caspase- 9 activity is hallmark of the intrinsic apoptotic pathway. To elucidate which apoptotic pathway is triggered in C12 induced cell death, we studied two pairs of MEF cells deficient in either caspase- 8 or caspase- 9 and their wild-type counterparts. Upon treatment with $\mathrm{C} 12$, similar levels of cell death were detected in both WT and caspase-8-KO MEF cells (Figure 3.4B). In agreement with cell death data, caspase-3/7 was activated regardless of caspase-8 expression, indicating that caspase-8-mediated extrinsic pathway is not involved in C12induced apoptosis in MEFs. In contrast, MEFs deficient in caspase-9 expression were completely resistant to $\mathrm{C} 12$ treatment (Figure 3.4E). Furthermore, $\mathrm{C} 12$ failed to evoke any significant activation of cspase3/7 (Figure 3.4F). Overall, these data suggest that $\mathrm{C} 12$ induces apoptotic signaling largely through activating the mitochondria-dependent intrinsic apoptotic pathway in MEFs. 


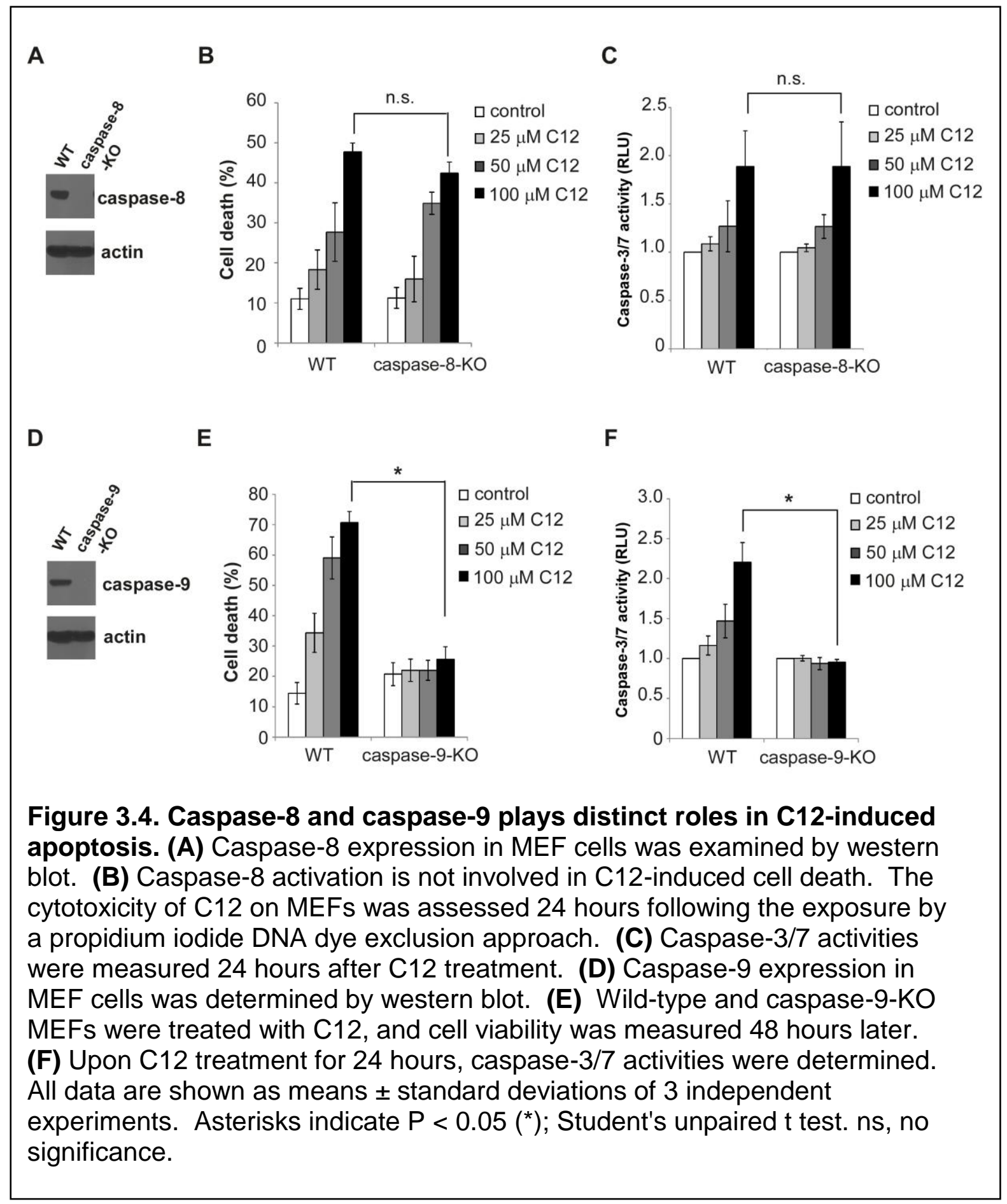


3.5. C12-induced mitochondrial potential decrease is independent of caspase-8 and caspase- 9 .

To further explore the roles of the "initiator" caspases in MOMP mediated by C12, depolarization of $\Delta \psi_{\text {mito }}$ was examined in caspase-8-KO or caspase-9-KO MEF cells or their WT counterparts respectively. Consistent with its effects on cell viability and caspase-3/7 activation (Figures 3.4B-C), deficiency in caspase-8 expression did not affect quick depolarization of $\Delta \psi_{\text {mito }}$ (Figures 3.5A-B). Similarly, C12 caused the same levels of $\Delta \psi_{\text {mito }}$ depolarization in WT and caspase-9-KO MEF cells (Figures 3.5C-D), indicating that the "initiator" caspases are not involved in C12- induced MOMP. 


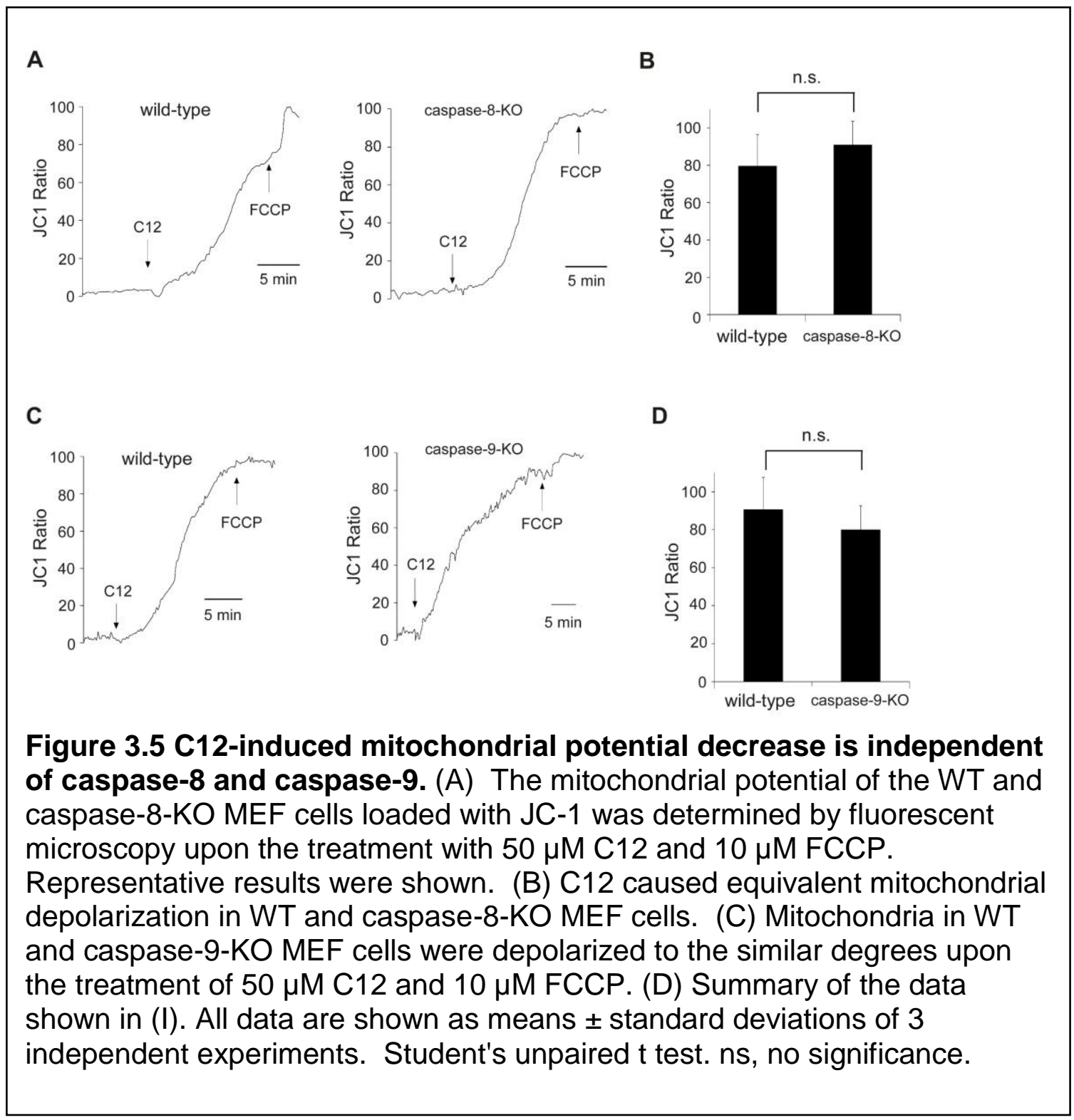


3.6. C12-induced caspase-9 activation occurs downstream of mitochondrial membrane permeabilization.

We have demonstrated that caspase-9 activation is involved in C12-induced apoptosis. To further elucidate the involvement of caspase- 9 activation, we examined cytochrome $\mathrm{c}$ redistribution from mitochondria to the cytosol/nuclei upon $\mathrm{C} 12$ exposure using immunofluorescence staining. While $\mathrm{C} 12$ evoked the release of cytochrome $\mathrm{c}$ from mitochondria to the cytosol/nuclei regardless of caspase-9 expression, Tom20 displayed typical punctate and perinuclear mitochondrial distribution following $\mathrm{C} 12$ treatment (Figure 3.6A). Moreover, $\mathrm{C} 12$ caused similar level of cytochrome c release from mitochondria in WT and caspase-9-KO MEF cells (Figure 3.6B). Taken together, these data indicate that C12 causes acute MOMP independent of any "initiator" caspase, suggesting that the effects of $\mathrm{C} 12$ on MOMP might be attributed to its direct action of on mitochondria. 


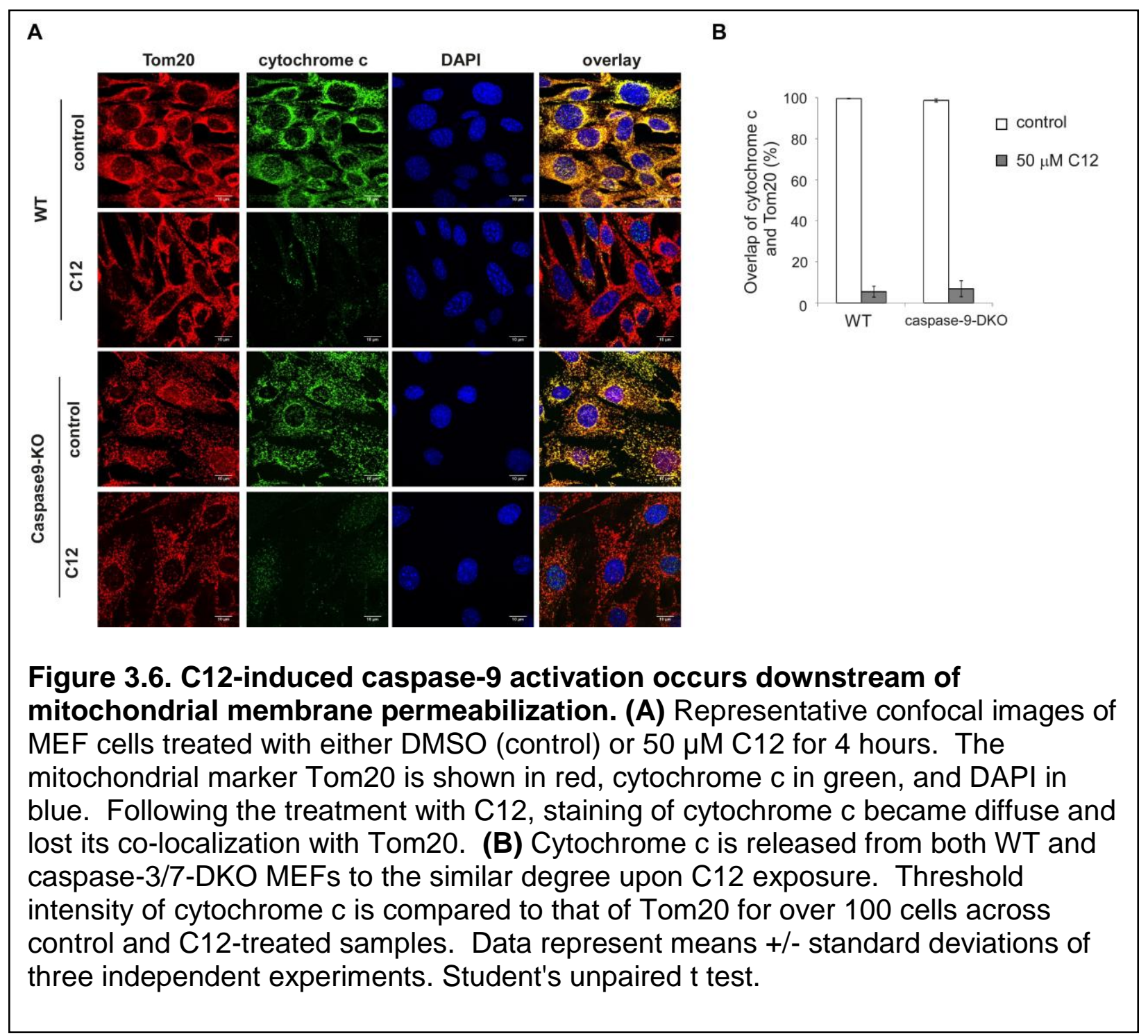


3.7. C12 directly induces mitochondrial outer membrane permeabilization in vitro. Since C12 depolarized $\Delta \psi_{\text {mito }}$ within minutes independent of both "initiator" caspases and "effector" caspases (Figures 3.2 and 3.5), we reasoned that C12 could possess activities directly permeabilize mitochondria. To this purpose, we examined the effects of $\mathrm{C} 12$ on mitochondrial outer membrane integrity in vitro. Mitochondria isolated from WT MEF cells were incubated various concentrations of $\mathrm{C} 12$. We assessed the amount of cytochrome $\mathrm{c}$ released from the mitochondria using western blot analysis (Figure 7A). In a manner dependent of C12 doses, less cytochrome $\mathrm{c}$ was detected in mitochondrial fractions with concurrent increase of cytochrome $\mathrm{c}$ in released fractions, indicating that $\mathrm{C} 12$ is able to permeabilize mitochondria directly in vitro. 


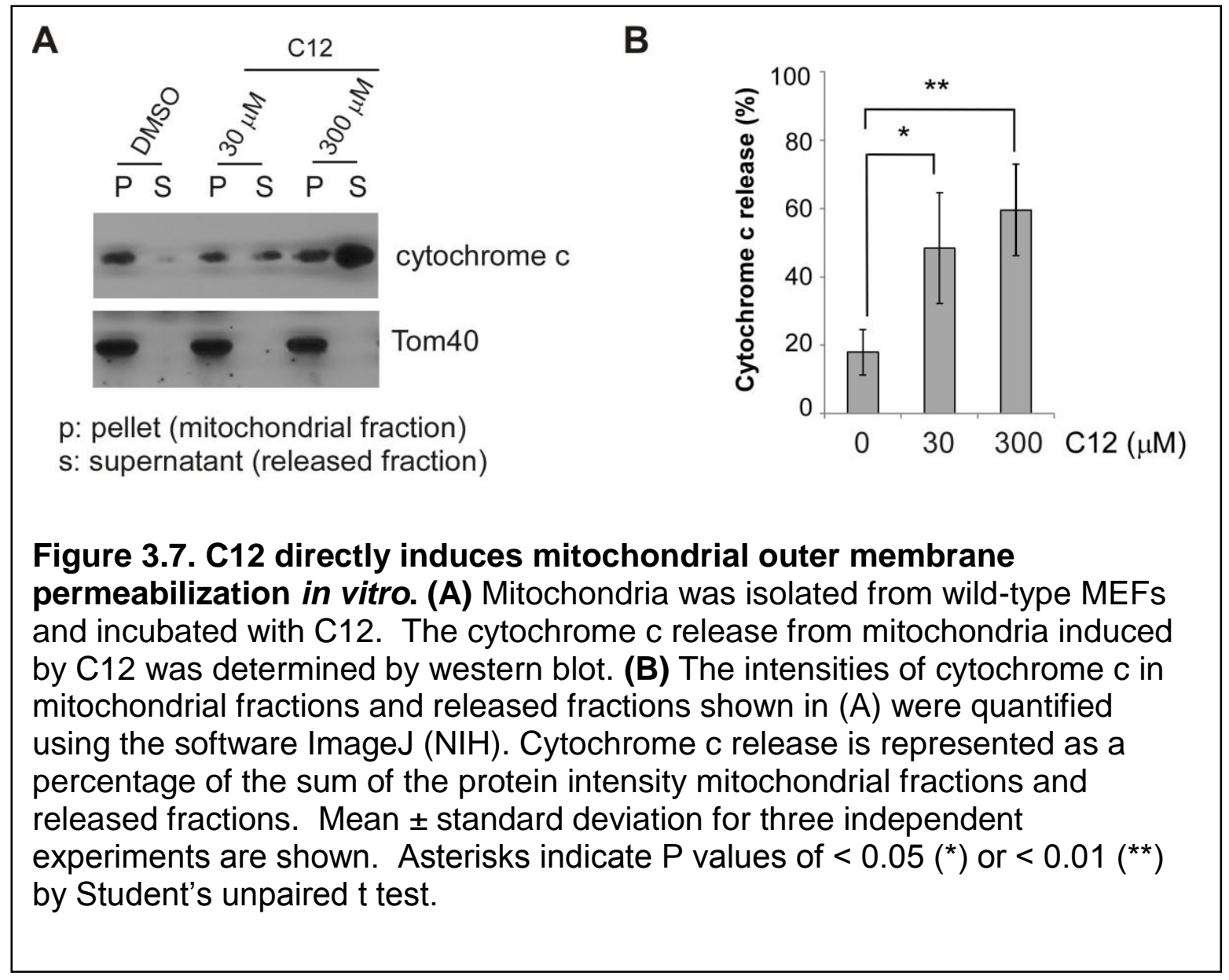


3.8. C12 forms channels with large conductance in phospholipid membranes in vitro.

The amphipathic lipid ceramide forms large stable permeation channels in the mitochondrial outer membrane capable of releasing proteins $(85,86)$. As C12 directly induce MOMP in vitro (Figure 3.7), we postulated that amphipathic $\mathrm{C} 12$ might possess similar activities. Thus, we studied whether $\mathrm{C} 12$ is capable of forming large conductance pathways in phospholipid membranes lacking any proteins. Following the addition of $\mathrm{C} 12$ to planar phospholipid membranes, the conductance increased slowly reaching steady levels but with frequent increases and decreases in conductance (Figure 8A). The formation of the conductance consisted of discrete conductance increments that are characteristic of channels with various magnitudes. Upon the addition of $\mathrm{LaCl}_{3}$, conductance formed by $\mathrm{C} 12$ was rapidly lost, suggesting that it was not caused by defects in the membrane (Figure 3.8A). This was reversed by chelation of the lanthanide with EDTA. Furthermore, the discrete conductance changes showed a log-normal distribution, which is typical of substances of varying size (Figure 3.8B). However, the distribution of conductance does not seem to be a continuum but rather shows indications of preferential conductance that is multiples of $16 \mathrm{nS}$. The results are consistent with $\mathrm{C} 12$ forming large channels of variable size that grow and shrink by incorporating or losing assemblies of C12 lipids, suggesting that $\mathrm{C} 12$ might directly function on mitochondria to induce MOMP (Figure 3.8D). 


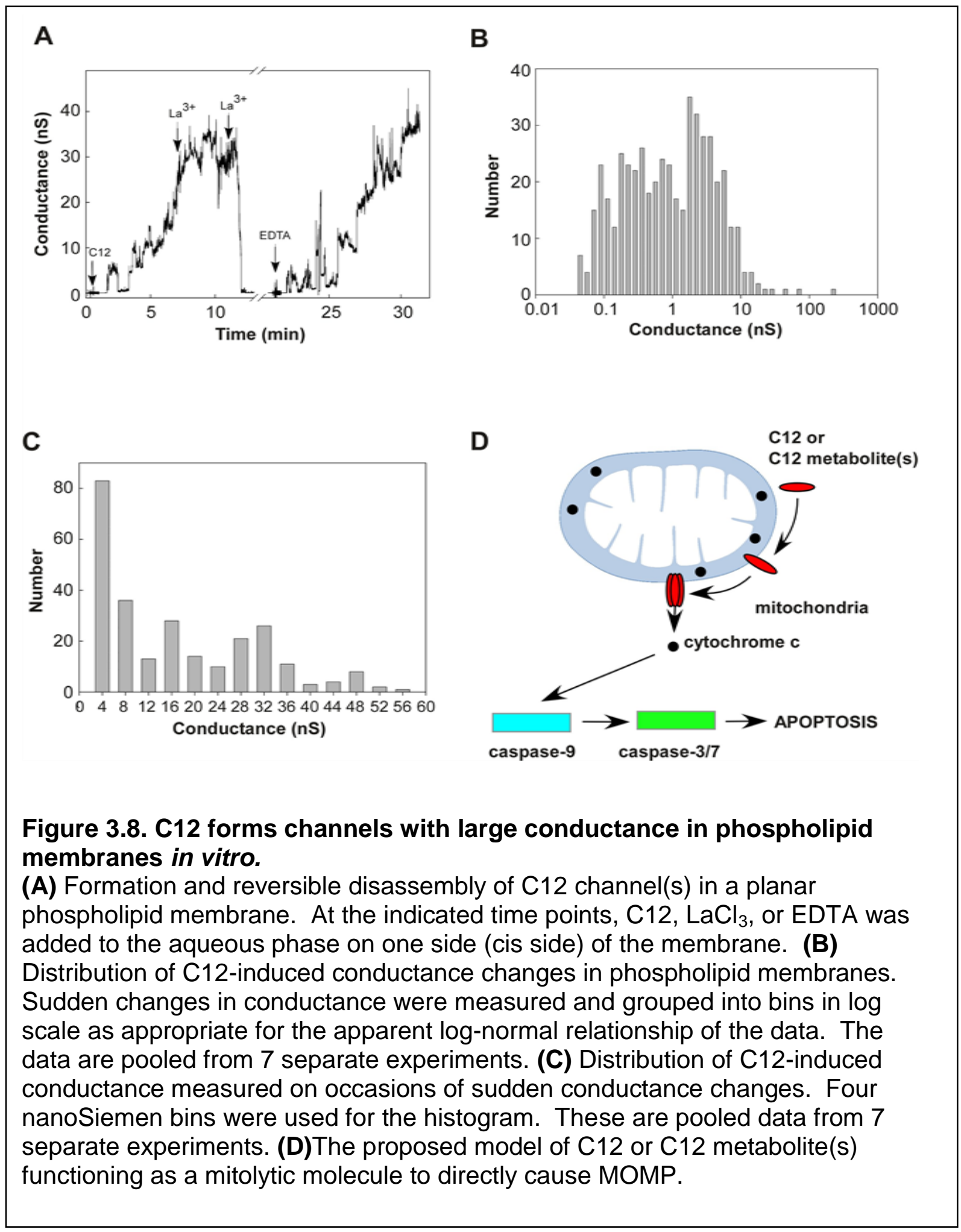


3.9. C12 inhibits LLC tumor growth and induces tumor cell apoptosis in vivo in a dose-dependent fashion.

The cytotoxic effects of $\mathrm{C} 12$ on tumor cells have been reported previously $(66,69,74,80)$, but whether they are selective for transformed cells was unknown. To investigate whether oncogenic transformation influences the cytotoxicity of $\mathrm{C} 12$, we studied normal human bronchia/tracheal epithelial (NHBE) and corresponding HBE immortalized and transformed successively by telomerase, SV40 large T antigen and activated Ras (H-ras V12). This is a well-established epithelial cell malignant transformation system related to human lung cancer (87). Upon C12 treatment, we observed higher levels of cell death and caspases-3/7 activation in transformed HBE cells than in their untransformed counterparts. This indicates that $\mathrm{C} 12$ induces apoptosis preferentially in transformed cells (Figure 3.9A-B). To investigate the relevance of $\mathrm{C} 12$ cytotoxicity on transformed cells to tumor growth in animals, we examined the effects of $\mathrm{C} 12$ on the growth of established Lewis Lung Carcinoma (LLC) tumors. We found that transplanted tumors grew much more slowly in C12-treated mice than in vehicle-treated mice, revealing a dose dependent anti-tumor activity of $\mathrm{C} 12$ as a single agent (Figure 3.9C). By evaluating caspase $3 / 7$ activation and TUNEL labeling, we found that apoptosis is involved in the inhibitory activity of $\mathrm{C} 12$ in vivo (Figure 3.9D-F). 


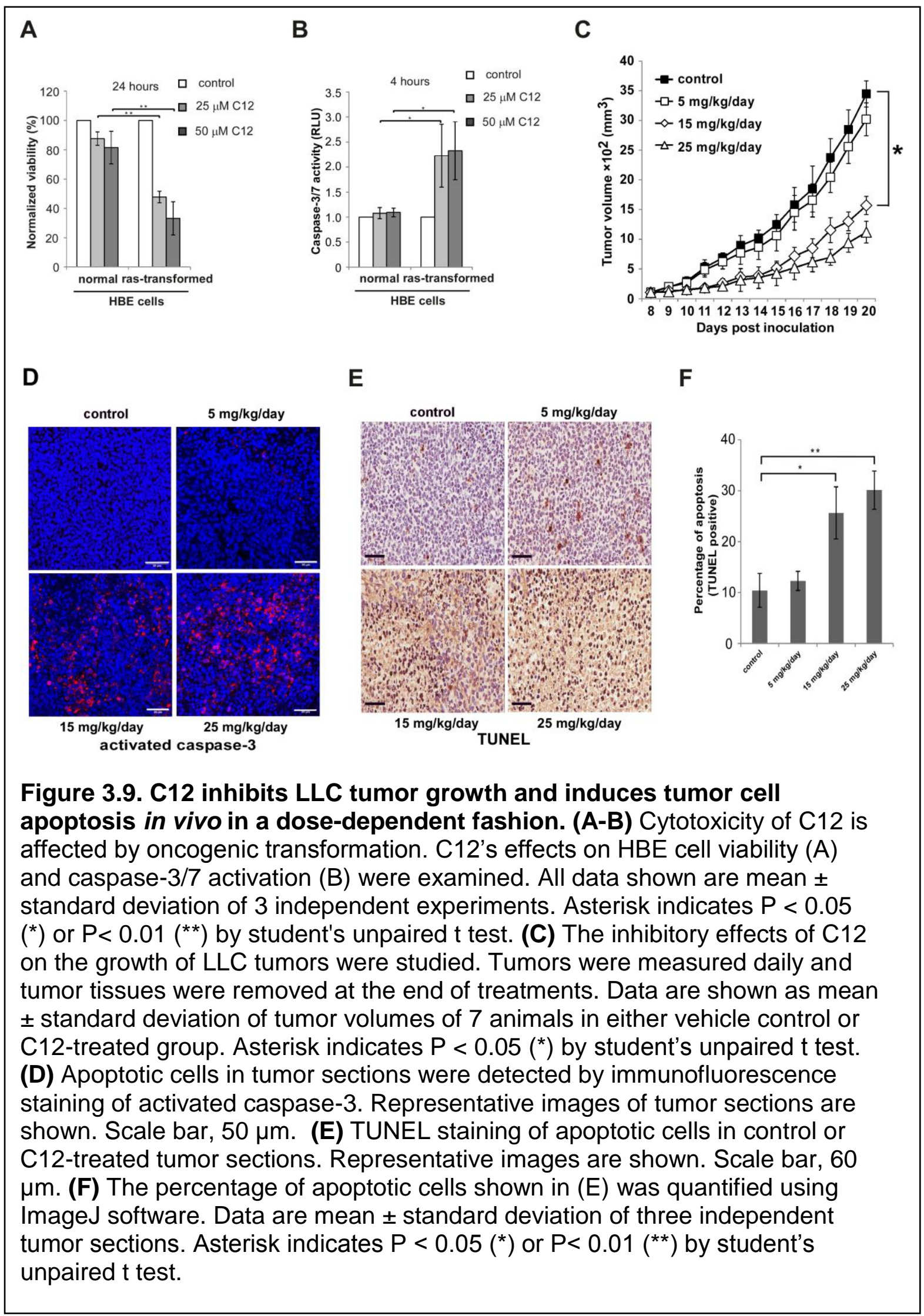


3.10. $\mathrm{C} 12$ induces tumor cell apoptosis independent of anti-apoptotic Bcl-2 proteins.

Anti-apoptotic Bcl-2 proteins are frequently overexpressed in human cancers and associated with chemotherapeutic resistance and relapse(88). To investigate the involvement of anti-apoptotic Bcl-2 proteins in C12-induced human tumor cell apoptosis, Bcl-2 was stably overexpressed in A549 cells by retroviral infection (Figure 3.10A). The anti-tumor drug actinomycin D caused less cell death and less caspases-3/7 activation in Bcl-2-overexpressing cells than in cells expressing the empty vector. In contrast, C12 induced similar levels of cell death and caspase-3/7 activation in cells overexpressing Bcl-2 and the vector control cells (Figure 3.10B-C). We also investigated whether C12's effect on mitochondrial membrane potential is dependent of Bcl-2. A549-vector and A549-Bcl-2-overexpressing cells were loaded with JC1, and its fluorescence was measured using imaging microscopy (Figure 3.10D-E). Within minutes of C12 exposure, mitochondria in A549-vector cells and A549Bcl-2 overexpressing cells were depolarized to the same degree, providing more evidence that $\mathrm{C} 12$ evokes apoptosis independent of anti-apoptotic Bcl-2 proteins. 


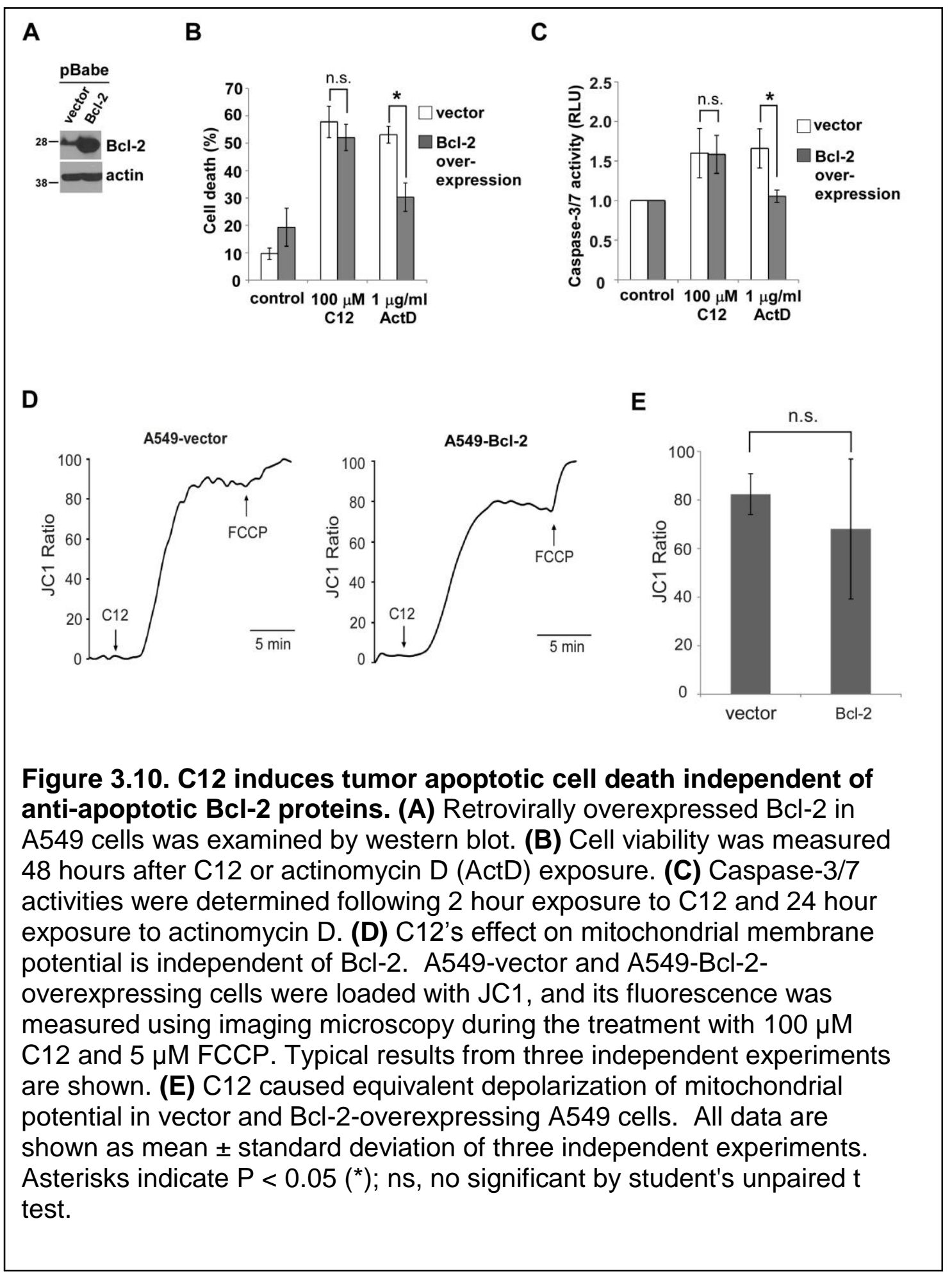


3.11. C12-induced tumor cell apoptosis is independent of Bak and Bax. Previous studies show that $\mathrm{C} 12$ induces apoptosis in MEFs independent of Bak and Bax (9), two pro-apoptotic Bcl-2 members required for MOMP in almost all apoptotic paradigms (3). To elucidate whether Bak and Bax are also involved in C12-induced tumor cell apoptosis, human colon carcinoma HCT116 cell lines deficient in Bak alone (Bak-KO), Bax alone (Bax-KO), or both Bak and Bax (Bak/Bax-DKO) were investigated (Figure 3.11A). We found that C12 caused equivalent cell death and caspase-3/7 activation in all the HCT116 cell lines examined (Figure 3.11B-C). This indicates that deficiency of Bak or Bax in HCT116 cells did not influence their responses to C12. Furthermore, deficiency in Bak/Bax expression did not affect C12's effect to depolarize $\Delta \psi_{\text {mito }}$ (Figure 3.11D-E). 


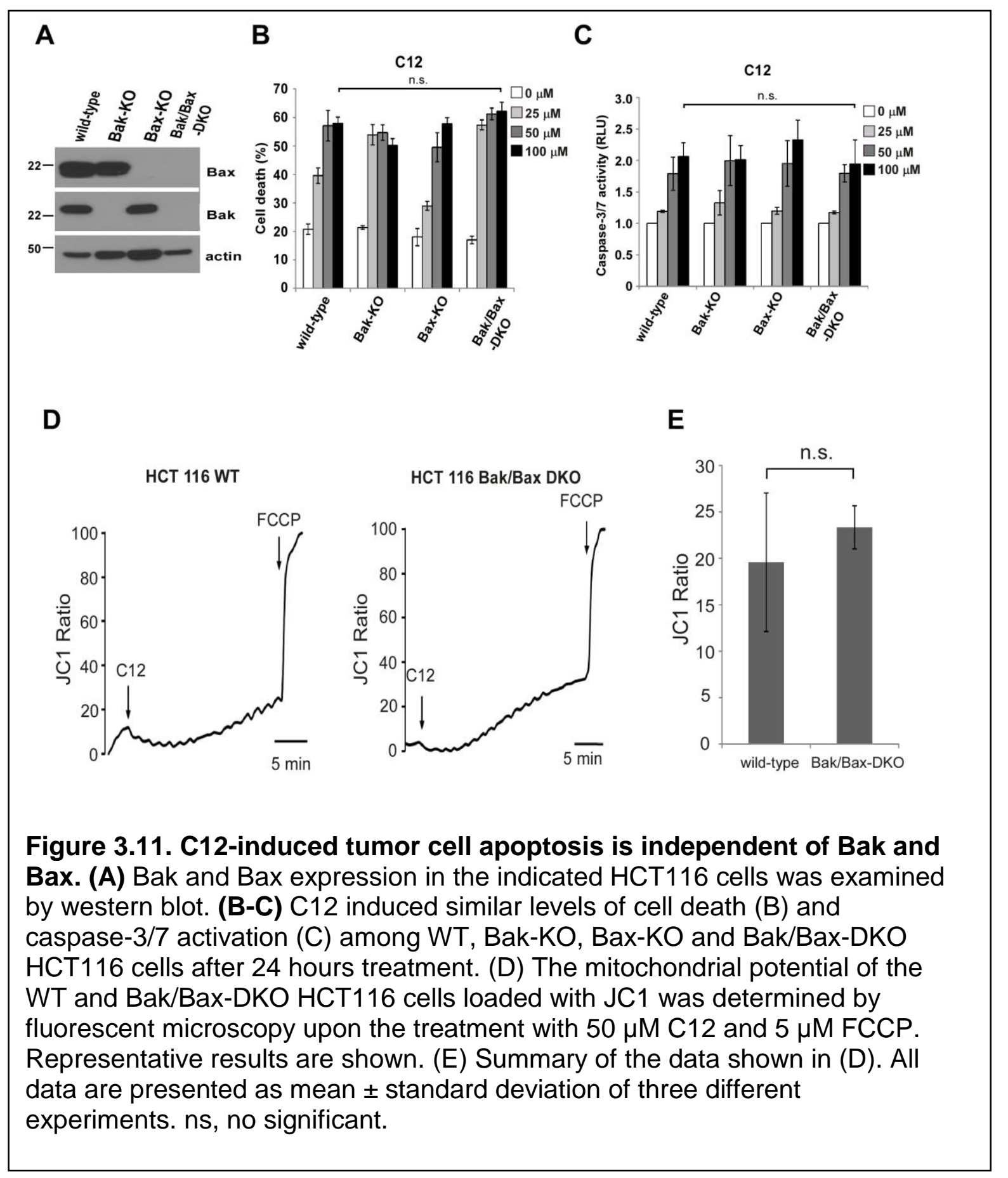


3.12. PON2 expression is enhanced in human lung tumor tissues and oncogenically transformed HBE cells.

It has been shown that PON2 upregulation in some cancer cells, including lung cancer cell lines, enables cancer cells to become resistant to conventional therapeutic drugs (80). To determine whether PON2 expression is enhanced in human lung cancer, we examined PON2 protein levels in tumor tissues of nonsmall cell lung carcinoma (NSCLC) patients by western blot. Among eleven samples from patients, we found that PON2 was overexpressed in eight of lung cancer tissues compared with corresponding adjacent normal tissues, whereas its expression was slightly decreased in three of them (Figure 3.12A). As Rastransformed HBE displayed higher levels of apoptosis compared with their untransformed counterparts upon $\mathrm{C} 12$ treatment (Figure 3.9A-B), PON2 expression was also increased in transformed HBE cells. These observations provide more evidence that oncogenic transformation enhances PON2 expression (Figure $3.12 \mathrm{C}$ ). 
A

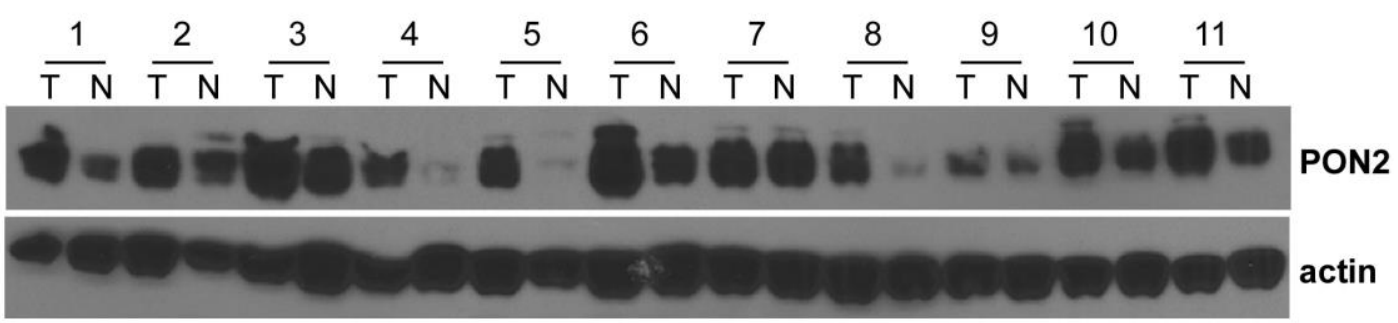

B

C
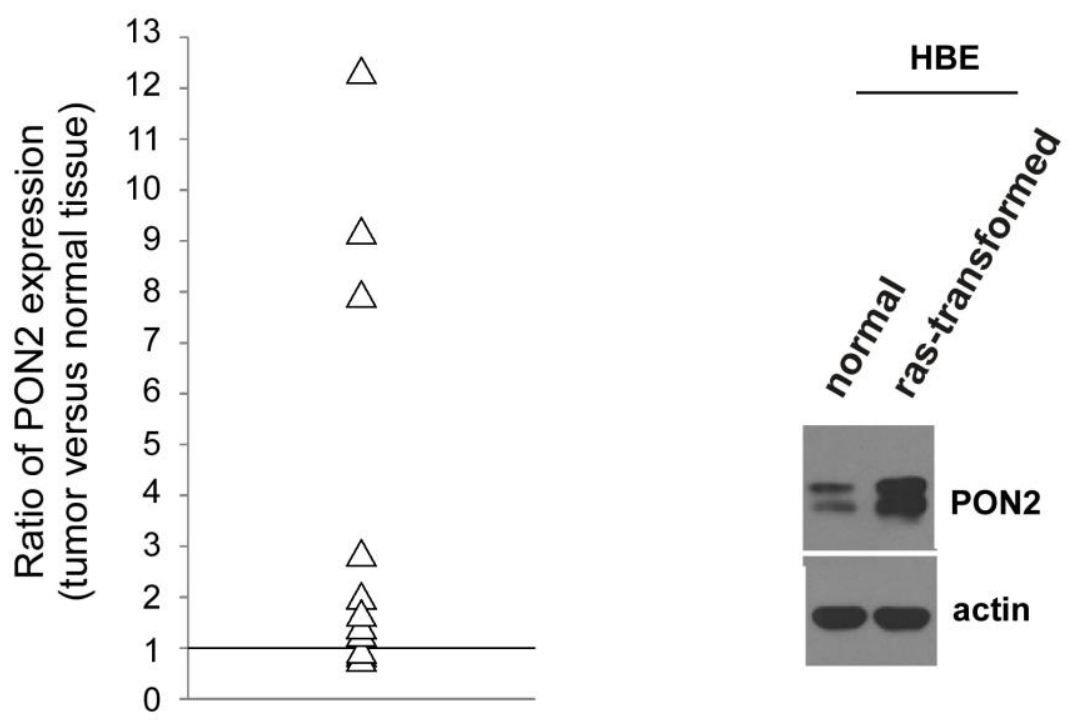

Figure 3.12. PON2 expression is enhanced in human lung tumor tissues and oncogenically transformed HBE cells. (A) Expression of PON2 in NSCLC tissue specimens and corresponding adjacent normal tissues from 11 patients were evaluated by western blot. Samples 1-4, 6, 8, 9, 11 were from adenocarcinoma patients, whereas samples $5,7,10$ were from squamous cell carcinoma patients. T, tumor; N, normal. (B) The intensities of bands in (A) were quantified using ImageJ software $(\mathrm{NIH})$. To normalize loading variation, the relative levels of PON2 were calculated by dividing the PON2 value into the corresponding value for actin. The data were shown as a ratio of PON2 levels in a tumor tissue sample versus its corresponding normal tissue, and the value bigger than 1 indicates that PON2 expression is increased in tumor tissues. Differential expression of PON2 in tumor versus normal tissues is significant with the value of "P" smaller than 0.01 as calculated by student's paired t test. (C) The expression of PON2 and PON3 in primary HBE cells and their transformed counterparts was determined by western blot. 
3.13. PON2 is required in $\mathrm{C} 12$ cytotoxicity in human lung tumor cells. Overexpression of PON2 promotes cytotoxicity of C12 in non-transformed MEF and HEK293T cells (9), but the role of endogenous PON2 in C12-induced apoptotic signaling is unclear. To further investigate the mechanism of $\mathrm{C} 12$ triggered apoptosis, we investigated the prospective involvement of endogenous PON2 in C12 cytotoxicity in tumor cells. We employed shRNA to stably reduce PON2 expression in human NSCLC cell lines A549 and NCI-H1299. Treatment with C12 elicited less cell death and caspase-3/7 activation in A549 and NCIH1299 cells lacking PON2 expression (Figure 3.13). Conversely, increased cell death and caspase-3/7 activation observed in PON2-deficient cells in response to the conventional apoptotic stimuli actinomycin D and tunicamycin, suggesting that PON2/C12 interaction induces a novel form of apoptosis distinct from that evoked by classical apoptotic stimuli (8) . 


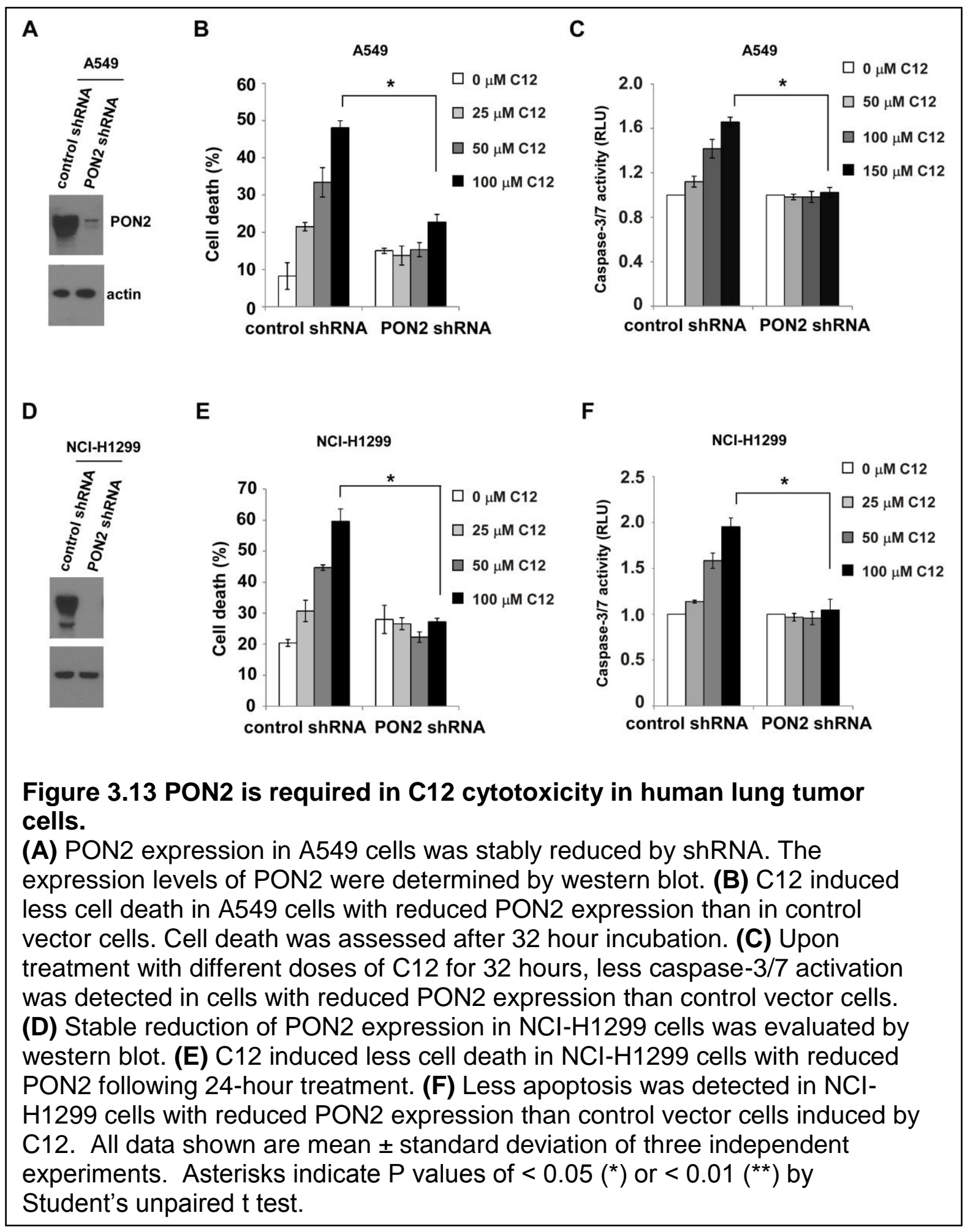


3.14. Murine PON2 sensitizes human lung tumor cells with reduced endogenous PON2 expression to $\mathrm{C} 12$.

To validate the role of PON2 in mediating C12-induced apoptosis, we stably overexpressed murine PON2 cDNA in A549 cells deficient in PON2 expression by retroviral infection (Figure 3.14A). Upon treatment with C12, we observed more cell death and caspase-3/7 activation in PON2-deficient A549 cells overexpressing murine PON2 compared to vector control and parental cells (Figure 3.14B). Similarly, stable overexpression of murine PON3 in PON2knockdown NCl-H1299 cells was confirmed by western blot (Figure 3.14C). We found that C12 induced more cell death and elicited higher caspase-3/7 activation in PON2-knockdown NCl-H1299 cells expressing mouse (Figure 3.14D). 


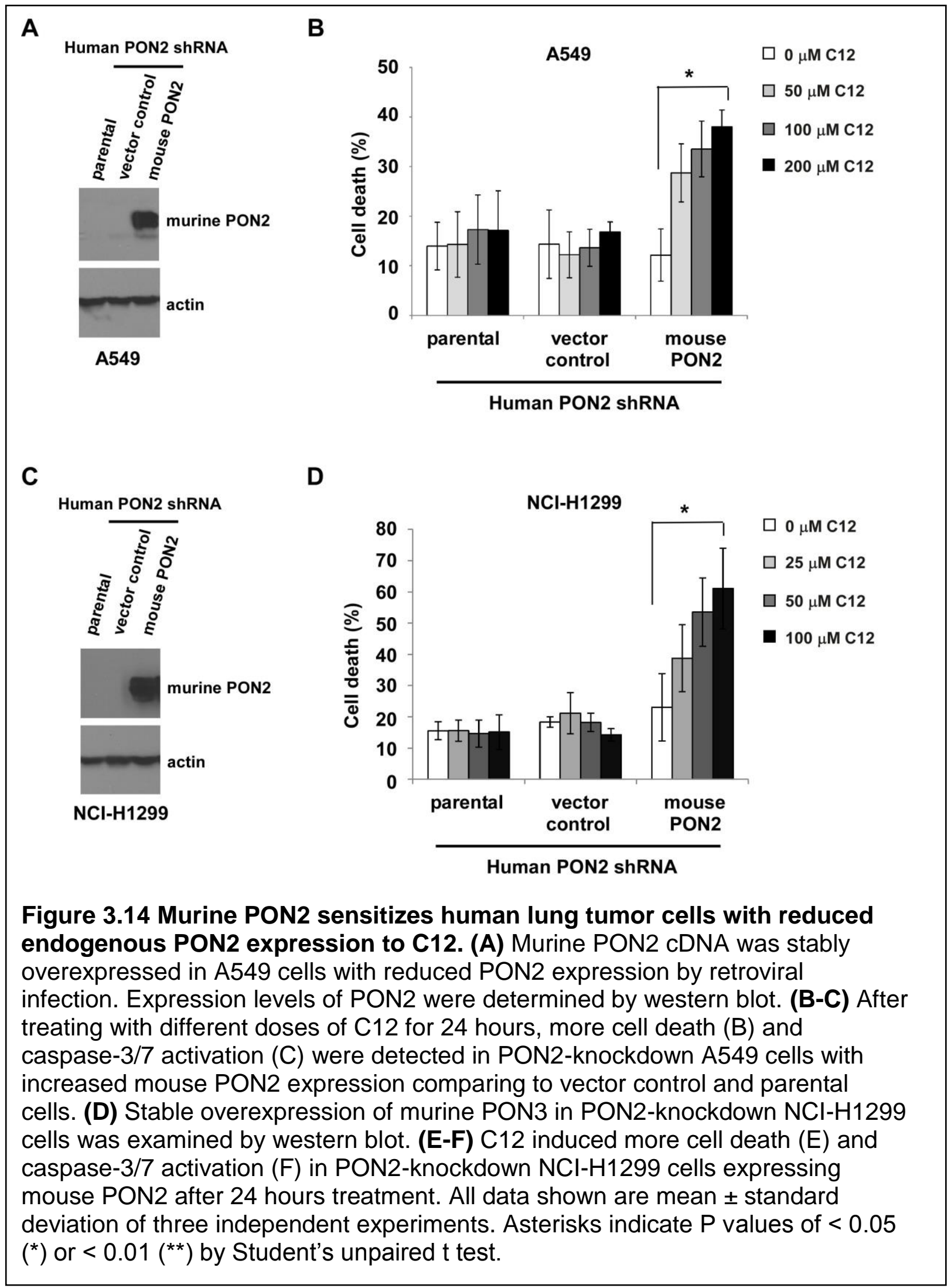


3.15. PON2 is essential for C12-triggered cell death in HEK-293T and HBE cells.

To further explore the involvement of PON2 in apoptotic signaling in nontransformed cells, endogenous PON2 expression was stably reduced in Human Embryonic Kidney-293T (HEK-293T) cells, whose viability was assessed upon treatment with C12 (Figure 3.15A-B). Reducing PON2 expression in HEK-293 cells enabled cells resistant to C12. Furthermore, we stably decreased PON2 expression in immortalized human bronchial epithelial (HBE) cells (89) and measured cell viability upon C12 exposure (Figure 3.15CD). Reducing PON2 expression in HBE cells de-sensitized cells to C12. Overall, these data provide evidence that PON2 plays a similar role in apoptotic signaling in both transformed and non-transformed cells. 
A

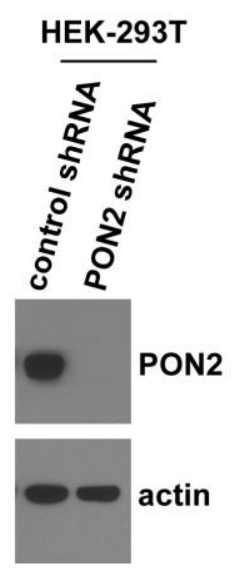

C

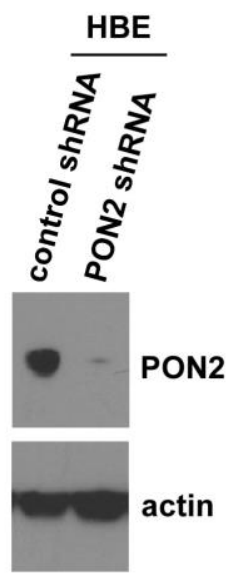

B

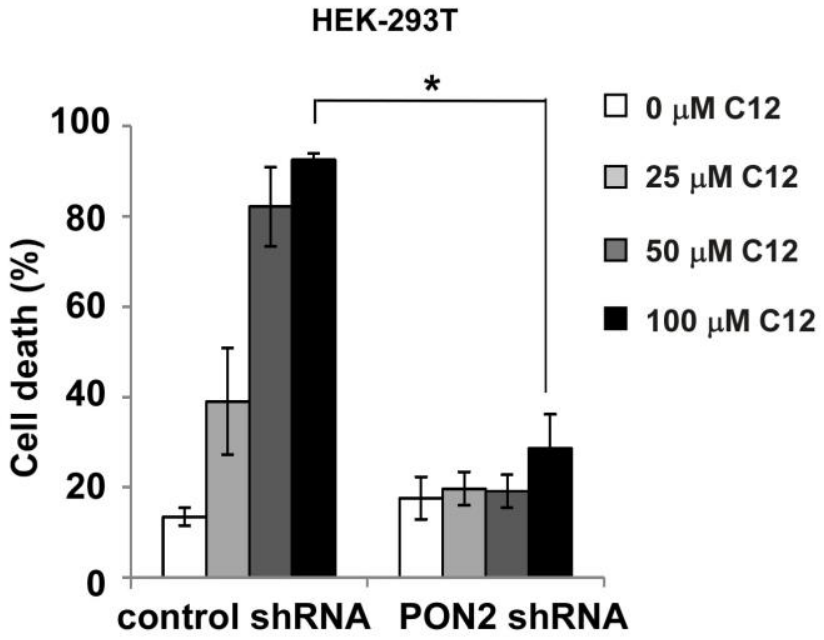

D

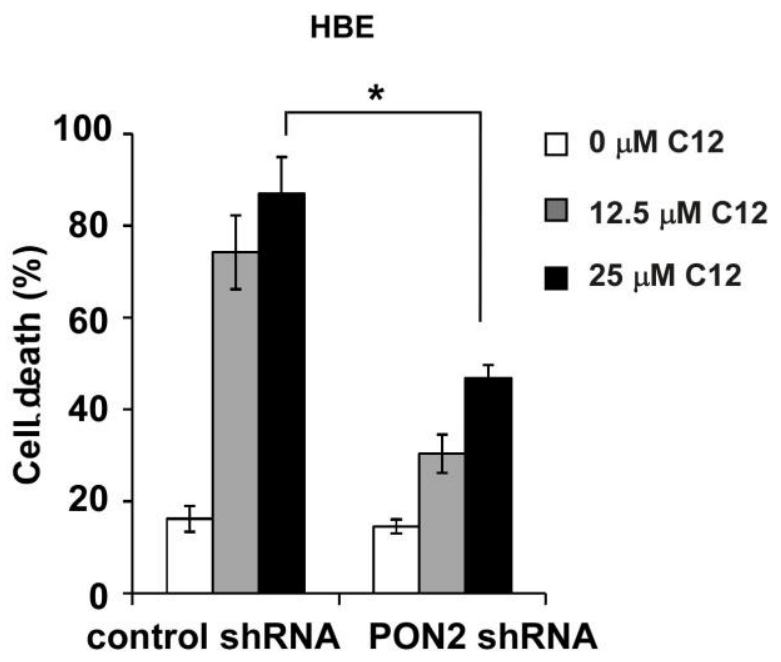

Figure 3.15 PON2 is essential for C12-triggered cell death in HEK-293T and HBE cells. (A) PON2 expression was stably reduced in HEK-293Tcells. (B) The viability of HEK-293Tcells was measured 24 hours after $\mathrm{C} 12$ treatment. (C) Stable decrease of PON2 expression in human bronchial epithelial (HBE) cells was determined by western blot. (D)The viability of HBE was evaluated 24 hours following $\mathrm{C} 12$ exposure. Mean \pm standard deviation for three independent experiments are shown. For all the data, ${ }^{*}, \mathrm{P}<0.05$, Student's unpaired $t$ test. 
3.16. PON2 is essential for human lung tumor cell proliferation but not nontransformed cell proliferation.

During the process of generating $\mathrm{A} 549$ and $\mathrm{NCl}-\mathrm{H} 1299$ cells lacking PON2 expression, we observed that those cells proliferated much slower than their vector control counterparts. To determine whether or not PON2 is essential for human lung tumor cell proliferation, we measured the proliferation of A549 cells and $\mathrm{NCl}-\mathrm{H} 1299$ expressing PON2 shRNA or the empty vector control. We found that proliferation of $\mathrm{NCl}-\mathrm{H} 1299$ and $\mathrm{A} 549$ cells with reduced PON2 expression was slower compared to that of their empty vector expressing counterparts (Figure 3.16A-B), implicating a role of PON2 in lung tumor cell proliferation. To determine whether or not PON2 is involved in the proliferation of non-transformed cells, we measured the proliferation of HEK-293T and HBE expressing PON2 shRNA or the empty vector control. It was found that HEK293T and HBE cells lacking PON2 expression grew at the same rate as their counterparts expressing the empty vector (Figure 3.16C-D), indicating that PON2 is not involved in non-transformed cell proliferation. Overall, these data indicate that PON2 mediates apoptosis independently of its function to modulate cell proliferation. 
A

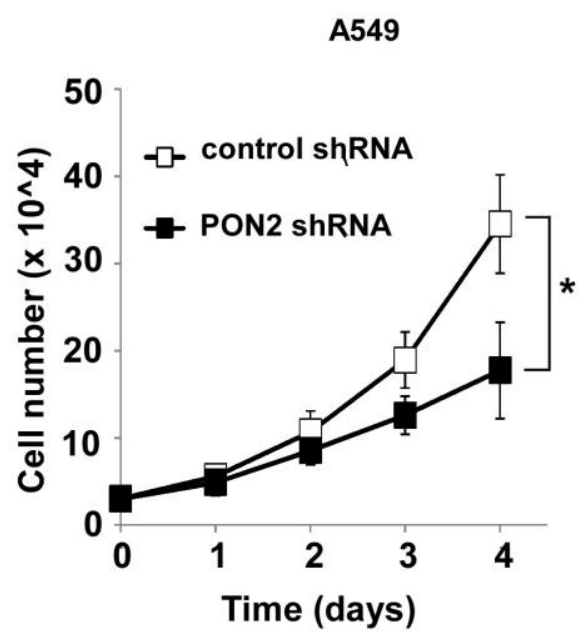

C

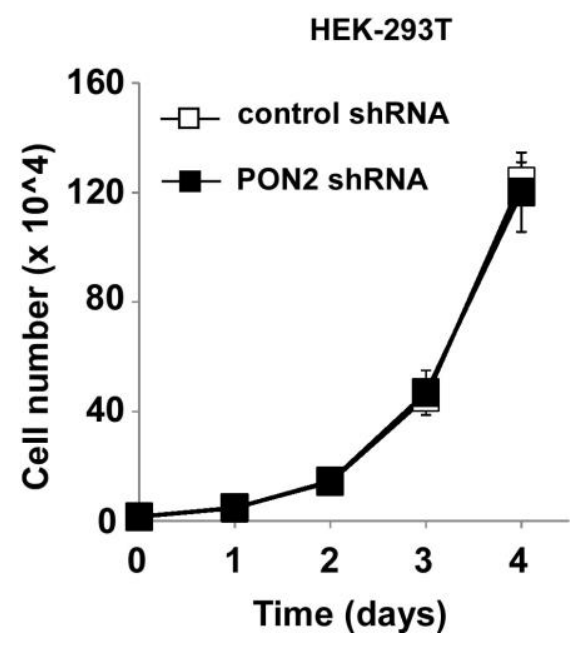

B

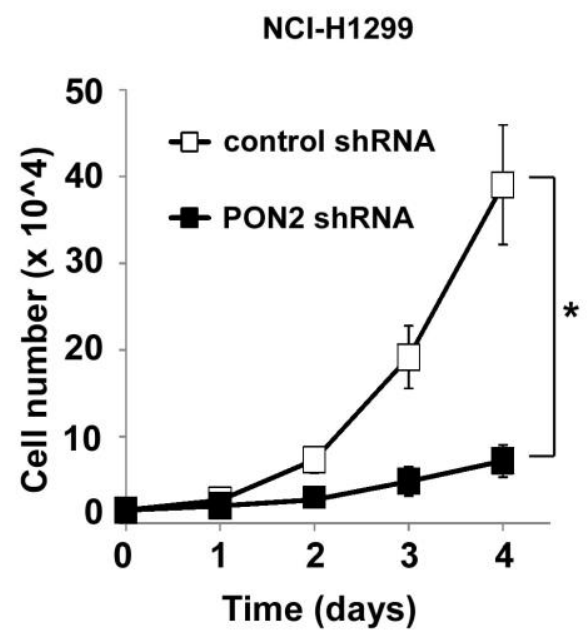

D

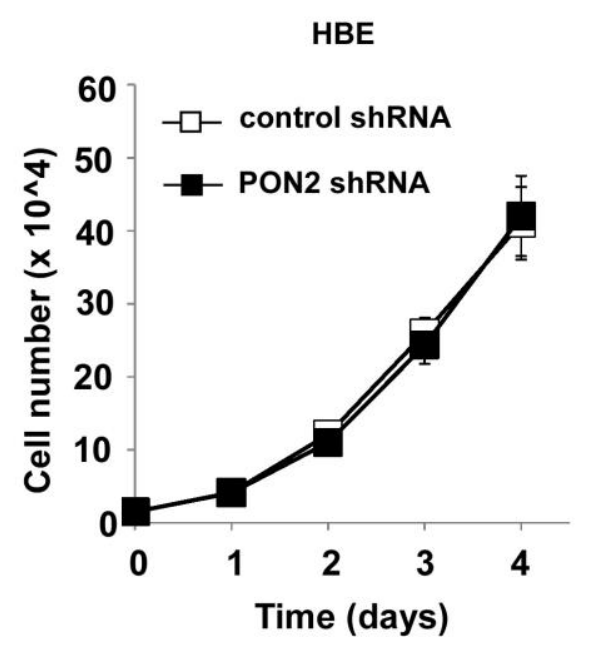

Figure 3.16 PON2 is essential for human lung tumor cell proliferation but not non-transformed cell proliferation. The proliferation of $A 549$ cells (A), $\mathrm{NCl}-\mathrm{H} 1299$ cells (B), HEK-293T cells (C) and HBE cells (D) expressing PON2 shRNA or the empty vector control was measured. Proliferation of NCl-H1299 and A549 cells with reduced PON2 expression was slower compared with their counterparts expressing the empty vector. HEK-293T cells (C) and HBE cells with reduced PON2 expression proliferated at the same rate as their vector control counterparts. All data shown are mean \pm standard deviation of three independent experiments. Asterisks indicate $P$ values of $<0.05\left(^{*}\right)$ by Student's unpaired $t$ test. 
3.17. Deficiency in PON2 expression induces $G 1$ cell cycle arrest of $A 549$ cells. To investigate the effects of deficient PON2 expression, we performed cell cycle analysis to determine the cell cycle profile of A549 cells expressing PON2 shRNA or the empty vector. We found that deficiency in PON2 expression induces cell cycle arrest at G1 phase in A549 cells (Figure 3.17). 
A
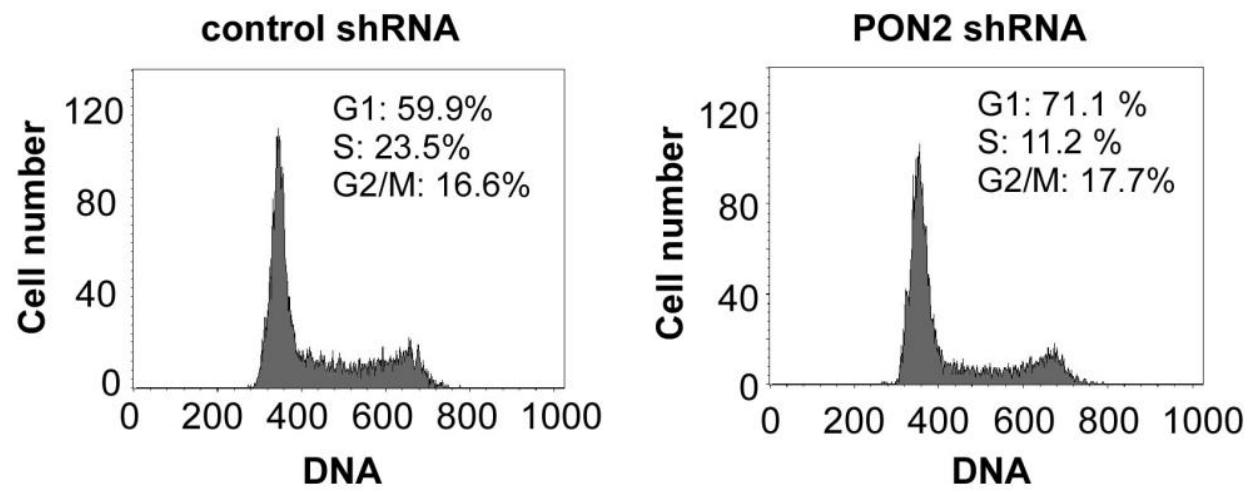

B

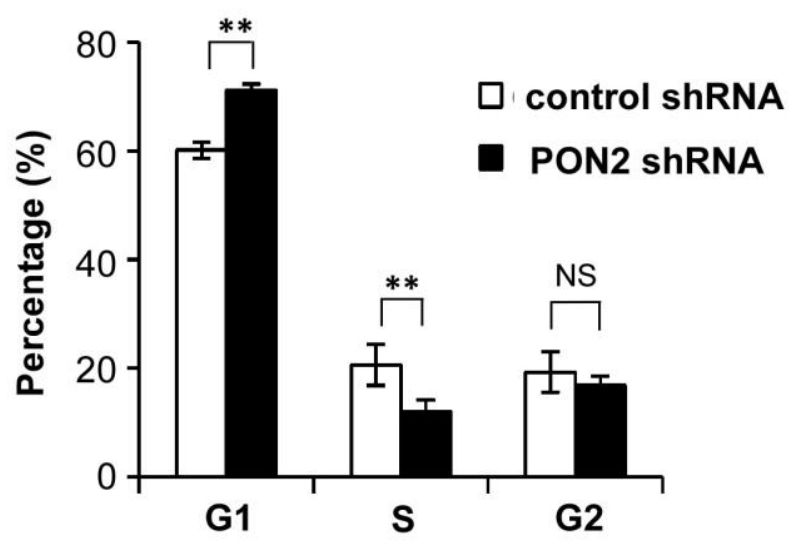

Figure 3.17. Deficiency in PON2 expression induces G1 cell cycle arrest of A549 cells. (A) Cell cycle profiles of A549 cells expressing PON2 shRNA or the empty vector control were determined. (B) Summary of the data shown in (A). Reducing PON2 expression caused higher percentage of the cells in G1 phase of cell cycle. All data shown are mean \pm standard deviation of three independent experiments. Asterisks indicate $P$ values of $<0.01\left(^{* *}\right)$ by Student's unpaired t test. "ns", no significance. 


\section{CHAPTER 4: DISCUSSION}

The quorum-sensing molecule $\mathrm{C} 12$ evokes apoptosis in a variety of mammalian cells $(62,65,68,90)$. Several signaling pathways leading to apoptosis have been associated with $\mathrm{C} 12$ cytotoxicity. In addition to the activation of the intrinsic apoptosis pathway, C12 is also shown to induce caspase-8 activation, suggesting a role of the extrinsic apoptosis cascade in C12-induced apoptosis (9). The interplay between these pathways and the functions of key molecules involved were still unclear. In this study using cells deficient in one or more caspases, we present evidence that caspase-3/7 and caspase- 9 but not caspase-8 are essential for C12-induced apoptotic cell death (Figures 3.1-3.2), indicating that $\mathrm{C} 12$ selectively triggers the mitochondria-dependent intrinsic apoptotic pathway. Previously reported C12-caused caspase-8 activation; in addition to the events associated with activating a plasma membrane receptor (e.g. TNF receptor), are likely secondary responses to MOMP. The dispensable roles of both "initiator" caspase (e.g. caspase-9) and "effector" caspase (e.g. caspase-3/7) in C12-indcued MOMP demonstrate that C12 may directly damage mitochondria without the involvement of other pathways triggering caspase activation.

Consistent with its ability to induce depolarization of $\Delta \psi_{\text {mito }}$ within 20 minutes (Figures 3.2 and 3.5), amphipathic C12 molecules assemble permeation 
channels in phospholipid membranes without any proteins (Figure 3.8). The characteristics of channels formed by $\mathrm{C} 12$ are similar to those of ceramide $(85,85)$. Ceramide has been demonstrated to suppress tumors through inhibiting tumor cell proliferation, triggering apoptosis, autophagy and/or senescence $(85,86)$. Ceramide-induced apoptosis signaling is modulated by both anti- and pro-apoptotic Bcl-2 proteins $(91,92)$. In agreement with their functions in apoptotic signaling, $\mathrm{Bcl}-2$ proteins also regulate ceramide channels in vitro $(93,94)$. It appears that $\mathrm{C} 12$ and ceramide evoke distinct apoptotic signaling with C12-triggered apoptotic responses independent of both anti- and pro-apoptotic Bcl-2 proteins in non-transformed as well as tumor cells.

Several signaling pathways linked to apoptosis initiation, including JAK/STAT pathway (66), MAPK and elF2 $\alpha$ pathways $(60)$, and ER stress pathway $(63,65)$, have been implicated in C12-evoked cell death. These apoptosis-associated signaling pathways are normally involved in multiple steps of signal transduction, and the biological events reflective of these signaling cascades are observed hours following $\mathrm{C} 12$ incubation. In contrast, depolarization of $\Delta \psi_{\text {mito }}$, the earliest step of MOMP (6), is always detected within minutes upon C12 exposure and reaches its maximal levels in 20 minutes as reported here (Figures 3.2 and 3.5) and in our earlier studies $(8,9)$. Thus, it appears that activation of these signaling pathways is secondary to MOMP initiation in C12-triggered apoptosis cascade. It is conceivable that $\mathrm{C} 12$ or its metabolite(s) acts directly on mitochondria to permeabilize them. The in vitro studies in this paper support the notion that $\mathrm{C} 12$ 
might directly assemble permeation channels on mitochondria, leading to cytochrome c release, apoptotic cascade activation, and ultimately apoptosis.

Many neoplastic cells show an increased ratio of anti-apoptotic to pro-apoptotic $\mathrm{Bcl}-2$ proteins, which enables them to survive even under the conditions that would normally initiate apoptotic signaling (95). An emerging strategy for cancer therapy is to overcome the resistance to apoptosis caused by aberrant $\mathrm{Bcl}-2$ signaling in tumor cells $(96,97)$. Recently, several small molecules triggering apoptosis independent of either pro- or anti-apoptotic $\mathrm{Bcl}-2$ proteins have been identified as potential anti-tumor drugs. Among them, the pentacyclic triterpenoid betulinic acid induces Bax/Bak-independent MOMP and subsequent apoptosis $(98,99)$. Unlike C12, cytotoxic effects of betulinic acid are influenced by Bcl-2 overexpression and it is ineffective against epithelial tumors. Similarly, Bax/Bak is also nonessential in apoptotic signaling induced by chelerythrine (100) or titanium dioxide $\left(\mathrm{TiO}_{2}\right)$ (101). The polyphenolic compound gossypol evokes Bax/Bak-independent apoptosis and inhibits Bcl-2-overexpressing human B lymphoblast tumor growth in nude mice (102). Furthermore, Bcl-2 expression fails to influence human tumor cell apoptosis induced by the antibiotic agent Tetrocarcin-A $(103,104)$. Compared with those molecules, C12 is the first small molecule compound, to the best of our knowledge, inducing human tumor cell apoptosis in vitro as well as blocking tumor growth in vivo independent of both pro- and anti-apoptotic Bcl-2 proteins. 
The apoptosis cascade induced by $\mathrm{C} 12$ in tumor cells is unique, evident by its rapid pro-apoptotic effects, such as depolarizing mitochondrial membrane potential within minutes (Figures 3.10 and 3.11), releasing cytochrome $\mathrm{c}$ into the cytosol and maximally activating caspases. These distinctive pro-apoptotic features of $\mathrm{C} 12$ have not been observed in any other apoptosis paradigms of cancer cells, which might be attributed to the ability of $\mathrm{C} 12$ or its derivatives generated in tumor cells to directly permeabilize mitochondria without the involvement of pro- and anti-apoptotic Bcl-2 proteins. This study also shows that endogenous PON2 is essential for C12's cytotoxicity in human lung tumor cells (Figure 3.13), which is consistent with our previous observation of PON2 overexpression in non-transformed fibroblasts and HEK293T cells (9). It has been reported that lung tumor cells are resistant to conventional therapeutic drugs partially due to enhanced expression of PON2, which is thought to be associated with anti-oxidant activities of PON2 $(78,79)$. Data presented in Figure 3.13 show decreased killing of A549 and NCl-H1299 cells with shRNA for PON2; which is consistent with previous results (9). Additionally, data in Figure 3.13 indicate that killing activities of $\mathrm{C} 12$ on lung tumor cells is mediated through PON2. Thus, it is conceivable that $\mathrm{C} 12$ or compounds derived from $\mathrm{C} 12$ could trigger rapid and $\mathrm{Bcl}-2$ protein-independent apoptosis in lung tumors that are resistant to traditional chemotherapeutic drugs, whereas normal tissues are spared due to their lower PON2 expression. 
PON2 is known to associate with the mitochondrial electron transport chain Complex III component coenzyme Q10 (CoQ10), and it is optimally positioned with appropriate enzymatic activity to cleave oxidized mitochondrial lipids $(73,105)$. One possibility is that enhanced PON2 expression in tumor cells functions by interacting with CoQ10, leading to increased mitochondrial electron transport, and subsequent mitochondrial bioenergetics, which generate enough ATP and metabolites to sustain the rapid proliferation of lung tumor cells. 


\section{CHAPTER 5: CONCLUSION}

Overall, our study reveals that $\mathrm{C} 12$ induces a unique mitochondrial apoptotic signaling pathway, in which $\mathrm{C} 12$ or $\mathrm{C} 12$ metabolite(s) acts on mitochondria as a mitolytic molecule to permeabilize mitochondria, leading to activation of apoptosis signaling independent of both pro- and anti-apoptotic Bcl-2 proteins. These properties of $\mathrm{C} 12$ enable it inhibit tumor growth as a single agent regardless of $\mathrm{Bcl}-2$ protein expression in tumors, making it an ideal candidate of a lead compound for novel therapeutic agents for cancer. Further to this, our studies indicate that PON2 expression in non-small cell lung carcinoma cells is essential for their rapid proliferation. Therefore, $\mathrm{C} 12$ is an ideal candidate of a lead compound for novel therapeutic agents for cancer. 


\section{REFERENCES}

1. Gilbert, S. F. (2003) Nat. Rev. Genet. 4, 735-741

2. Cory, S. and Adams, J. M. (2002) Nat. Rev. Cancer 2, 647-656

3. Hardwick, J. M. and Youle, R. J. (2009) Cell 138, 404, 404

4. Adams, J. M. and Cory, S. (2007) Curr. Opin. Immunol. 19, 488-496

5. Fesik, S. W. (2005) Nat. Rev. Cancer 5, 876-885

6. Chipuk, J. E. and Green, D. R. (2008) Trends Cell Biol. 18, 157-164

7. Irie, Y. and Parsek, M. R. (2008) Curr. Top. Microbiol. Immunol. 322, 67-84

8. Zhao, G., Neely, A. M., Schwarzer, C., Lu, H., Whitt, A. G., Stivers, N. S., Burlison, J. A., White, C., Machen, T. E., and Li, C. (2016) Oncotarget.

9. Schwarzer, C., Fu, Z., Morita, T., Whitt, A. G., Neely, A. M., Li, C., and Machen, T. E. (2015) J. Biol. Chem. 290, 7247-7258

10. Reed, J. C. (1999) J. Clin. Oncol. 17, 2941-2953

11. Vaux, D. L. and Korsmeyer, S. J. (1999) Cell 96, 245-254

12. Ziegler, U. and Groscurth, P. (2004) News Physiol Sci. 19, 124-128

13. Fuchs, Y. and Steller, H. (2011) Cell 147, 742-758

14. Cory, S., Huang, D. C., and Adams, J. M. (2003) Oncogene 22, 8590-8607

15. Tibbetts, M. D., Zheng, L., and Lenardo, M. J. (2003) Nat. Immunol. 4, 404-409

16. Jenner, P. (2003) Ann. Neurol. 53 Suppl 3, S26-S36

17. Upham, B. L. and Wagner, J. G. (2001) Toxicol. Sci. 64, 1-3

18. Petros, A. M., Olejniczak, E. T., and Fesik, S. W. (2004) Biochim. Biophys. Acta $1644,83-94$

19. Petros, A. M., Olejniczak, E. T., and Fesik, S. W. (2004) Biochim. Biophys. Acta $1644,83-94$ 
20. Fadeel, B. and Orrenius, S. (2005) J. Intern. Med. 258, 479-517

21. Ellis, R. E., Yuan, J. Y., and Horvitz, H. R. (1991) Annu. Rev. Cell Biol. 7, 663698

22. Xu, D., Li, Y., Arcaro, M., Lackey, M., and Bergmann, A. (2005) Development $132,2125-2134$

23. Gelbard, H. A., Boustany, R. M., and Schor, N. F. (1997) Pediatr. Neurol. 16, $93-$ 97

24. Fairweather, D., Kaya, Z., Shellam, G. R., Lawson, C. M., and Rose, N. R. (2001) J. Autoimmun. 16, 175-186

25. Renehan, A. G., Booth, C., and Potten, C. S. (2001) BMJ 322, 1536-1538

26. King, C., Ilic, A., Koelsch, K., and Sarvetnick, N. (2004) Cell 117, 265-277

27. Coultas, L. and Strasser, A. (2003) Semin. Cancer Biol. 13, 115-123

28. Henry-Mowatt, J., Dive, C., Martinou, J. C., and James, D. (2004) Oncogene 23, $2850-2860$

29. Srinivasula, S. M., Datta, P., Fan, X. J., Fernandes-Alnemri, T., Huang, Z., and Alnemri, E. S. (2000) J. Biol. Chem. 275, 36152-36157

30. Wajant, H. (2002) Science 296, 1635-1636

31. Boldin, M. P., Varfolomeev, E. E., Pancer, Z., Mett, I. L., Camonis, J. H., and Wallach, D. (1995) J. Biol. Chem. 270, 7795-7798

32. Chinnaiyan, A. M., O'Rourke, K., Tewari, M., and Dixit, V. M. (1995) Cell 81, 505-512

33. Wang, J., Chun, H. J., Wong, W., Spencer, D. M., and Lenardo, M. J. (2001) Proc. Natl. Acad. Sci. U. S. A 98, 13884-13888

34. Bao, Q. and Shi, Y. (2007) Cell Death. Differ. 14, 56-65

35. Ashkenazi, A. (2002) Nat. Rev. Cancer 2, 420-430

36. Fulda, S. and Debatin, K. M. (2006) Oncogene 25, 4798-4811

37. Boatright, K. M. and Salvesen, G. S. (2003) Curr. Opin. Cell Biol. 15, 725-731

38. Saraste, A. and Pulkki, K. (2000) Cardiovasc. Res. 45, 528-537

39. Shi, Y. (2004) Cell 117, 855-858 
40. Lamkanfi, M., Festjens, N., Declercq, W., Vanden Berghe, T., and Vandenabeele, P. (2007) Cell Death. Differ. 14, 44-55

41. Knezevich, S., Ludkovski, O., Salski, C., Lestou, V., Chhanabhai, M., Lam, W., Klasa, R., Connors, J. M., Dyer, M. J., Gascoyne, R. D., and Horsman, D. E. (2005) Leukemia 19, 659-663

42. Youle, R. J. and Strasser, A. (2008) Nat. Rev. Mol. Cell Biol. 9, 47-59

43. Tsujimoto, Y. (2003) J. Cell Physiol 195, 158-167

44. Hsu, S. Y., Kaipia, A., McGee, E., Lomeli, M., and Hsueh, A. J. (1997) Proc. Natl. Acad. Sci. U. S. A 94, 12401-12406

45. Antonsson, B., Montessuit, S., Sanchez, B., and Martinou, J. C. (2001) J. Biol. Chem. 276, 11615-11623

46. Hsu, Y. T., Wolter, K. G., and Youle, R. J. (1997) Proc. Natl. Acad. Sci. U. S. A 94, 3668-3672

47. Mikhailov, V., Mikhailova, M., Degenhardt, K., Venkatachalam, M. A., White, E., and Saikumar, P. (2003) J. Biol. Chem. 278, 5367-5376

48. Glick, D., Barth, S., and Macleod, K. F. (2010) J. Pathol. 221, 3-12

49. Saftig, P., Beertsen, W., and Eskelinen, E. L. (2008) Autophagy. 4, 510-512

50. Glick, D., Barth, S., and Macleod, K. F. (2010) J. Pathol. 221, 3-12

51. Eskelinen, E. L. (2008) Autophagy. 4, 257-260

52. Kroemer, G., El-Deiry, W. S., Golstein, P., Peter, M. E., Vaux, D., Vandenabeele, P., Zhivotovsky, B., Blagosklonny, M. V., Malorni, W., Knight, R. A., Piacentini, M., Nagata, S., and Melino, G. (2005) Cell Death. Differ. 12 Suppl 2, 1463-1467

53. Edinger, A. L. and Thompson, C. B. (2004) Curr. Opin. Cell Biol. 16, 663-669

54. Festjens, N., Vanden Berghe, T., and Vandenabeele, P. (2006) Biochim. Biophys. Acta 1757, 1371-1387

55. Zong, W. X. and Thompson, C. B. (2006) Genes Dev. 20, 1-15

56. Yuan, J. (2006) Mol. Cell 23, 1-12

57. Zitvogel, L., Casares, N., Pequignot, M. O., Chaput, N., Albert, M. L., and Kroemer, G. (2004) Adv. Immunol. 84, 131-179

58. Miller, M. B. and Bassler, B. L. (2001) Annu. Rev. Microbiol. 55, 165-199 
59. Schuster, M. and Greenberg, E. P. (2006) Int. J. Med. Microbiol. 296, 73-81

60. Kravchenko, V. V. and Kaufmann, G. F. (2013) Cell Microbiol. 15, 527-536

61. Telford, G., Wheeler, D., Williams, P., Tomkins, P. T., Appleby, P., Sewell, H., Stewart, G. S., Bycroft, B. W., and Pritchard, D. I. (1998) Infect. Immun. 66, 3642

62. Kravchenko, V. V., Kaufmann, G. F., Mathison, J. C., Scott, D. A., Katz, A. Z., Grauer, D. C., Lehmann, M., Meijler, M. M., Janda, K. D., and Ulevitch, R. J. (2008) Science 321, 259-263

63. Valentine, C. D., Zhang, H., Phuan, P. W., Nguyen, J., Verkman, A. S., and Haggie, P. M. (2014) Cell Microbiol. 16, 1-14

64. Grabiner, M. A., Fu, Z., Wu, T., Barry, K. C., Schwarzer, C., and Machen, T. E. (2014) J. Immunol. 193, 1459-1467

65. Schwarzer, C., Fu, Z., Patanwala, M., Hum, L., Lopez-Guzman, M., Illek, B., Kong, W., Lynch, S. V., and Machen, T. E. (2012) Cell Microbiol. 14, 698-709

66. Li, L., Hooi, D., Chhabra, S. R., Pritchard, D., and Shaw, P. E. (2004) Oncogene $23,4894-4902$

67. Shiner, E. K., Terentyev, D., Bryan, A., Sennoune, S., Martinez-Zaguilan, R., Li, G., Gyorke, S., Williams, S. C., and Rumbaugh, K. P. (2006) Cell Microbiol. 8, $1601-1610$

68. Valentine, C. D., Anderson, M. O., Papa, F. R., and Haggie, P. M. (2013) PLoS. Pathog. 9, e1003576

69. Oliver, C. M., Schaefer, A. L., Greenberg, E. P., and Sufrin, J. R. (2009) J. Med. Chem. 52, 1569-1575

70. Kumar, A. S., Bryan, J. N., and Kumar, S. R. (2014) PLoS. One. 9, e106480

71. Dolnick, R., Wu, Q., Angelino, N. J., Stephanie, L. V., Chow, K. C., Sufrin, J. R., and Dolnick, B. J. (2005) Cancer Res. 65, 5917-5924

72. Schweikert, E. M., Amort, J., Wilgenbus, P., Forstermann, U., Teiber, J. F., and Horke, S. (2012) J. Lipids 2012, 352857

73. Devarajan, A., Bourquard, N., Hama, S., Navab, M., Grijalva, V. R., Morvardi, S., Clarke, C. F., Vergnes, L., Reue, K., Teiber, J. F., and Reddy, S. T. (2011) Antioxid. Redox. Signal. 14, 341-351

74. Horke, S., Xiao, J., Schutz, E. M., Kramer, G. L., Wilgenbus, P., Witte, I., Selbach, M., and Teiber, J. F. (2015) Infect. Immun. 83, 3369-3380 
75. Chun, C. K., Ozer, E. A., Welsh, M. J., Zabner, J., and Greenberg, E. P. (2004) Proc. Natl. Acad. Sci. U. S. A 101, 3587-3590

76. Draganov, D. I., Teiber, J. F., Speelman, A., Osawa, Y., Sunahara, R., and La Du, B. N. (2005) J. Lipid Res. 46, 1239-1247

77. Stoltz, D. A., Ozer, E. A., Ng, C. J., Yu, J. M., Reddy, S. T., Lusis, A. J., Bourquard, N., Parsek, M. R., Zabner, J., and Shih, D. M. (2007) Am. J. Physiol Lung Cell Mol. Physiol 292, L852-L860

78. Witte, I., Altenhofer, S., Wilgenbus, P., Amort, J., Clement, A. M., Pautz, A., Li, H., Forstermann, U., and Horke, S. (2011) Cell Death. Dis. 2, e112

79. Witte, I., Foerstermann, U., Devarajan, A., Reddy, S. T., and Horke, S. (2012) J. Lipids 2012, 342806

80. Witte, I., Altenhofer, S., Wilgenbus, P., Amort, J., Clement, A. M., Pautz, A., Li, H., Forstermann, U., and Horke, S. (2011) Cell Death. Dis. 2, e112

81. Witte, I., Foerstermann, U., Devarajan, A., Reddy, S. T., and Horke, S. (2012) J. Lipids 2012, 342806

82. Zhao, G., Wang, J., Wang, X., Chen, S., Zhao, Y., Gu, F., Xu, A., and Wu, L. (2011) Environ. Sci. Technol. 45, 1638-1644

83. Zhao, G., Lu, H., and Li, C. (2015) J. Biol. Chem. 290, 8949-8963

84. Schweikert, E. M., Devarajan, A., Witte, I., Wilgenbus, P., Amort, J., Forstermann, U., Shabazian, A., Grijalva, V., Shih, D. M., Farias-Eisner, R., Teiber, J. F., Reddy, S. T., and Horke, S. (2012) Cell Death. Differ. 19, 15491560

85. Colombini, M. (2010) Biochim. Biophys. Acta 1797, 1239-1244

86. Morad, S. A. and Cabot, M. C. (2013) Nat. Rev. Cancer 13, 51-65

87. Soejima, K., Fang, W., and Rollins, B. J. (2003) Oncogene 22, 4723-4733

88. Kelly, P. N. and Strasser, A. (2011) Cell Death. Differ. 18, 1414-1424

89. Delgado, O., Kaisani, A. A., Spinola, M., Xie, X. J., Batten, K. G., Minna, J. D., Wright, W. E., and Shay, J. W. (2011) PLoS. One. 6, e22023

90. Li, H., Wang, L., Ye, L., Mao, Y., Xie, X., Xia, C., Chen, J., Lu, Z., and Song, J. (2009) Med. Microbiol. Immunol. 198, 113-121

91. Scorrano, L., Oakes, S. A., Opferman, J. T., Cheng, E. H., Sorcinelli, M. D., Pozzan, T., and Korsmeyer, S. J. (2003) Science 300, 135-139 
92. Lin, C. F., Chen, C. L., Chang, W. T., Jan, M. S., Hsu, L. J., Wu, R. H., Fang, Y. T., Tang, M. J., Chang, W. C., and Lin, Y. S. (2005) J. Biol. Chem. 280, 2375823765

93. Siskind, L. J., Feinstein, L., Yu, T., Davis, J. S., Jones, D., Choi, J., Zuckerman, J. E., Tan, W., Hill, R. B., Hardwick, J. M., and Colombini, M. (2008) J. Biol. Chem. 283, 6622-6630

94. Ganesan, V. and Colombini, M. (2010) FEBS Lett. 584, 2128-2134

95. Evan, G. I. and Vousden, K. H. (2001) Nature 411, 342-348

96. Vogler, M., Dinsdale, D., Dyer, M. J., and Cohen, G. M. (2009) Cell Death. Differ. 16, 360-367

97. Certo, M., Del, G. M., V, Nishino, M., Wei, G., Korsmeyer, S., Armstrong, S. A., and Letai, A. (2006) Cancer Cell 9, 351-365

98. Mullauer, F. B., Kessler, J. H., and Medema, J. P. (2010) Anticancer Drugs 21, 215-227

99. Mullauer, F. B., Kessler, J. H., and Medema, J. P. (2009) Apoptosis. 14, 191-202

100. Wan, K. F., Chan, S. L., Sukumaran, S. K., Lee, M. C., and Yu, V. C. (2008) J. Biol. Chem. 283, 8423-8433

101. Zhu, Y., Eaton, J. W., and Li, C. (2012) PLoS. One. 7, e50607

102. Lei, X., Chen, Y., Du, G., Yu, W., Wang, X., Qu, H., Xia, B., He, H., Mao, J., Zong, W., Liao, X., Mehrpour, M., Hao, X., and Chen, Q. (2006) FASEB J. 20, 2147-2149

103. Anether, G., Tinhofer, I., Senfter, M., and Greil, R. (2003) Blood 101, 4561-4568

104. Hallgren, O., Gustafsson, L., Irjala, H., Selivanova, G., Orrenius, S., and Svanborg, C. (2006) Apoptosis. 11, 221-233

105. Devarajan, A., Grijalva, V. R., Bourquard, N., Meriwether, D., III, Imaizumi, S., Shin, B. C., Devaskar, S. U., and Reddy, S. T. (2012) Mol. Genet. Metab 107, 416-427 


\section{APPENDIX: LIST OF ABBREVIATIONS}

\begin{tabular}{ll} 
5-FU & 5-Fluorouracil \\
Apaf-1 & Apoptotic Protease Factor 1 \\
BH & Bcl-2 homolog \\
C12 & N-(3-oxododecanoyl)-homoserine lactone \\
COQ10 & Coenzyme Q10 \\
DISC & Death Inducing Signaling Complex \\
FADD & Fas Associated Death Domain \\
FasL & Fas Ligand \\
FBS & Fetal Bovine Serum \\
IAPs & Inhibitor of Apoptosis Proteins \\
LLC & Lewis Lung Carcinoma \\
MEFs & Mouse Embryonic Fibroblasts \\
MIPs & Maximum Intensity Projections \\
MOMP & Mitochondrial Outer Membrane Permeabilization \\
NHBE & Puman Bronchi/Tracheal Epithelial Cells \\
NSCLC & Non-Small Cell Lung Carcinoma \\
OMM & Outer Mitochondrial Membrane \\
PBS & Phosphate Buffered Saline \\
PI & Praoxonase 2 \\
PON2 & Hodide \\
\hline
\end{tabular}




$\begin{array}{ll}\text { ROIS } & \text { Regions of Interest } \\ \text { TLR4 } & \text { Toll-Like Receptor } 4 \\ \text { TNF } & \text { Tumor Necrosis Factor } \\ \text { TNFR } & \text { Tumor Necrosis Factor Receptor } \\ \text { TNFR1 } & \text { Tumor Necrosis Factor Receptor 1 } \\ \text { TRAIL } & \text { TNF-Related Apoptosis Inducing Ligand } \\ \text { WT } & \text { Wild Type }\end{array}$




\section{CURRICULUM VITAE}

\section{AARON MACKALLAN NEELY}

PRESENT ADDRESS: Department of Pharmacology and Toxicology, School of Medicine, University of Louisville, 505 S Hancock St. Rm 433A Louisville, KY 40202

TELEPHONE:

(469)682-5909

EMAIL:

aaron neely@hotmail.com; amneel04@louisville.edu

PLACE OF BIRTH: Nassau, Bahamas

DATE OF BIRTH: $\quad$ April, $25^{\text {th }} 1983$

VISA STATUS: $\quad$ F1 Visa

EDUCATION:

08/2013-present: Ph.D., Department of Pharmacology and Toxicology, University of Louisville, Louisville, Kentucky

08/2009-08/2012: M.S., Biology (Developmental Physiology), University of North Texas, Denton, Texas

8/2003-05/2007: B.Sc., Biology, Paul Quinn College, Dallas,Texas

PROFESSIONAL EXPERIENCE:

08/2013-present: Graduate Research assistant, Department of Pharmacology and Toxicology, University of Louisville, Louisville, Kentucky (Advisor Dr. Chi Li)

02/2012-08/2013: Recovery Analyst, Real Time Resolutions- Chase Department, Dallas, Texas (Supervisor Jordan Schnieder)

06/2011-08/2012: Teacher's Assistant/Lab Instructor-Introduction to Biology I, University of North Texas, Denton, Texas

01/2011-05/2011: Teacher's Assistant/Lab Instructor-Animal Physiology, University of North Texas, Denton, Texas

01/2010-12/2010: Teacher's Assistant/Lab Instructor- Human Anatomy \& 
Physiology I, University of North Texas, Denton, Texas

01/2009-12/2009: Teacher's Assistant/Lab Instructor- Human Anatomy and

Physiology II, University of North Texas, Denton, Texas

01/2009- 05/2012: Graduate Research assistant, Department of Biology, University of Texas, Denton, Texas (Advisor Edward Dzialowski)

09/2001-12/2008: Customer Service Representative/ Personal Banker, The Royal Bank of Canada, Nassau, Bahamas (Supervisor Natasha, Huyler)

07/2000-08/2001: Office Clerk, The Private Trust Corporation (PTC), Nassau, Bahamas (Supervisor Kenya Pickersgill)

PROFESSIONAL MEMBERSHIPS:

2015- present: Society of Toxicology

2004-present: Phi Eta Sigma Honor Society

MAJOR AWARDS AND SCHOLARSHIPS:

2013-2015: University of Louisville Integrated Program in Biomedical Sciences (IPIBS) Doctoral Fellowship

2009-2012: University of North Texas Physiology Graduate Assistantship, Denton, Texas

University of North Texas Biology Teacher's Assistantship, Denton, Texas

The Good Neighbor Scholarship, Denton, Texas

2003-2007: International Student Scholarship, Paul Quinn College, Dallas, Texas, Track and Field Scholarship, Paul Quinn College, Dallas Texas

PUBLICATIONS:

Christian Schwarzer, Zhu Fu, Takeshi Morita, Aaron G. Whitt, Aaron M. Neely, Chi Li and Terry E. Machen (2015) Paraoxonase 2 mediates N-(3-

oxododecanoyl)-homoserine lactone-triggered apoptosis in fibroblasts. Journal Biological Chemistry. 290:8949-8963. PMID:25697356.

Guoping Zhao, Aaron M. Neely, Christian Schwarzer, Huayi Lu, Aaron G. Whitt, Joseph A. Burlison, Terry E. Machen and Chi Li. (2016) N-(3-oxo-

acyl)homoserine lactone inhibits tumor growth independent of $\mathrm{Bcl}-2$ proteins. Oncotarget. 10.18632/oncotarget.6827. PMID: 26758417.

ABSTRACTS SUBMITTED TO REGIONAL AND NATIONAL MEETINGS: Neely, A.M., Zhao, G., Whitt A., and Li, C. Distinct roles of paraoxonase 2 in apoptosis signaling cell proliferation. Research!Louisville. September 2015.

Neely, A.M., Zhao, G., Stivers, N.S., and Li, C. The Psuedomonas aeruginosa quarum-sensing molecule homoserine lactone triggers a unique mitochondrial 
apoptotic signaling pathway. Ohio Valley Society of Toxicology Student/PostDoc Summer Meeting. June 2015.

Neely, A.M., Zhao, G., Stivers, N.S., and Li, C. The Psuedomonas aeruginosa quarum-sensing molecule homoserine lactone triggers a unique mitochondrial apoptotic signaling pathway. University of Louisville Graduate Student Research Symposium. November 2014.

Neely, A.M., Zhao, G., Stivers, N.S., and Li, C. The Psuedomonas aeruginosa quarum-sensing molecule homoserine lactone triggers a unique mitochondrial apoptotic signaling pathway. James Graham Brown Cancer Retreat. November 2014.

Neely, A.M., Zhao, G., Stivers, N.S., and Li, C. The Psuedomonas aeruginosa quarum-sensing molecule homoserine lactone triggers a unique mitochondrial apoptotic signaling pathway. Research!Louisville. October 2014.

\section{TECHNICAL SKILLS:}

CELL AND MOLECULAR BIOLOGY TECHNIQUES:

Polymerase chain reaction (PCR), reverse transcriptase PCR (rtPCR), quantitative real time PCR ( $\mathrm{PPCR}$ ), molecular cloning, Mitochondrial Purification, western blot analysis, flow cytometry analysis, immunoprecipitation (IP), immunofluescence analysis, retroviral infection, microscopy, cell culture.

ANIMAL HANDLING TECHNIQUES:

Measurement of Metabolic Rates (Oxygen Consumption): Chicken (Gallus gallus), Alligator and Muscovy ducks

\section{COMPUTER SKILLS:}

Microsoft office (MS word, MS Excel, MS power point), Adobe

Photoshop, Canvas, EndNote 9, Reference Manager 